\title{
VARIABILITY OF HAWAI'IAN WINTER RAINFALL DURING LA NIÑA EVENTS SINCE 1956
}

\section{A THESIS SUBMITTED TO THE GRADUATE DIVISION OF THE UNIVERSITY OF HAWAI'I AT MĀNOA IN PARTIAL FULFILLMENT OF THE REQUIREMENTS FOR THE DEGREE OF}

\author{
MASTER OF SCIENCE \\ IN \\ METEOROLOGY
}

AUGUST 2014

\author{
By \\ Chris F. O'Connor \\ Thesis Committee: \\ Pao-Shin Chu, Chairperson \\ Yuqing Wang \\ Rashed Chowdhury
}

Keywords: ENSO, La Niña, Hawaiian rainfall 


\section{ACKNOWLEDGEMENTS}

Foremost, I would like to express my sincere gratitude to my advisor Dr. Pao-Shin Chu for the continuous support of my MS research, for his patience, motivation, leadership, and guidance throughout the entire process. Besides my advisor, I would like to thank the rest of my thesis committee, Dr. Yuqing Wang and Dr. Rashed Chowdhury, for their encouragement and insightful comments. My sincere appreciation also goes to Dr. Pang-chi Hsu, for offering ongoing assistance with interpretation and coding of the moisture budget analysis. I thank my fellow research group members in Dr. Chu's Research Group, Dr. Andre Marquez, Christopher Holloway, Kristine Tofte, and Christopher Wrenn, for their stimulating discussions and critiques. Special thanks must go to Dr. Marquez, for his immense tutoring in Ferret, WRF, and Matlab; without his assistance this research would not have been possible. Also I want to thank Kevin Kodama of the Honolulu National Weather Service for supplying the motivation which lead to the beginning of this project. Thomas Robinson was a tremendous aid in learning OpenGrADS, and I want to thank him for all his support during the course of this study. Next, Robert Ballard of the Honolulu National Weather Service was of great support in finding NASA storm track data. Last but not least, Dr. Aaron Levine was a great mentor throughout MS program, and I greatly appreciate his selflessness and willingness to help. 


\begin{abstract}
Rainfall trends in Hawai'i during La Niña years have undergone abnormal variability since the early 1980s, making seasonal forecasts more challenging to perform. Traditionally, Hawai'i receives greater than normal precipitation during La Niña wet seasons. Recently, the wet seasons of La Niña years have experienced less than normal rainfall. A change-point analysis has been performed to determine that the shift in precipitation occurs in 1983, forming two epochs in the study used for comparison. The first epoch runs from 1956 to 1982 and the second epoch spreads from 1983 to 2010. A normalized rainfall anomaly assessment is performed, illustrating the drying trend in Hawai'ian precipitation during La Niña years. Furthermore, location specific changes in rainfall anomalies throughout the Hawai'ian Islands are examined. Influenced by variations in tropical sea surface temperatures, circulation features in the northern Pacific Ocean have changed during La Niña wet seasons.
\end{abstract}

Strengthening, broadening, and westward shifting of the eastern North Pacific subtropical high, coupled with an eastward elongation and intensification of the subtropical jet stream, are two main influencers when considering the lack of precipitation during the recent La Niña wet seasons. Moisture transport analysis shows that variations in circulation structures are the greatest cause for a reduction of moisture in the Hawai'ian region during the second epoch. Additionally, a storm track analysis reveals that the changes found in the aforementioned circulation features are creating a less favorable environment for the development of Kona lows and midlatitude fronts in the vicinity of Hawai'i. A case study concerning North Pacific precipitation analysis of two contrasting years is also performed. 


\section{TABLE OF CONTENTS}

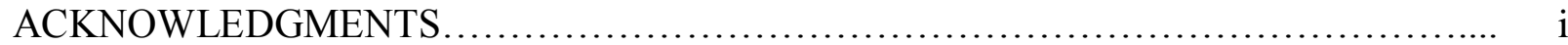

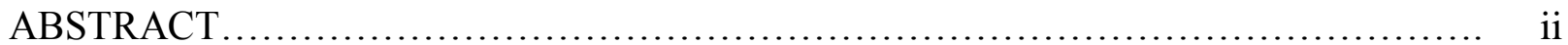

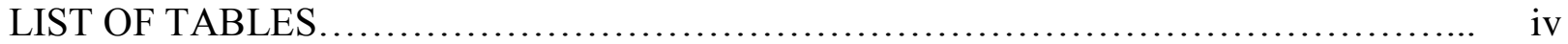

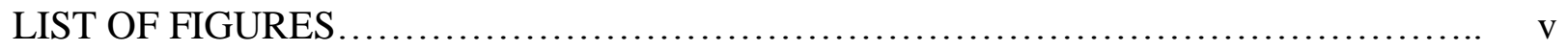

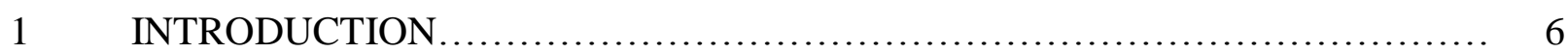

2 DATA

$2.1 \quad$ Time Period ..................................................................... 12

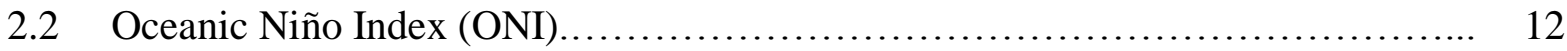

$2.3 \quad$ Rainfall Gauge Data....................................................... 13

2.4 Circulation Data....................................................... 13

2.5 Global Precipitation Data.................................................. 14

3 METHODOLOGY............................................................ 15

$3.1 \quad$ Normalized Rainfall Data................................................... 15

3.2 Change-Point Detection Method and Hypothesis Testing ...................... 16

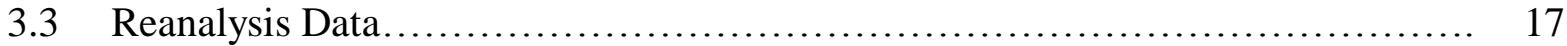

3.4 Moisture Transport Analysis............................................... 17

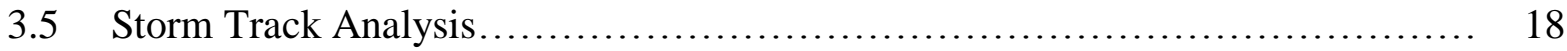

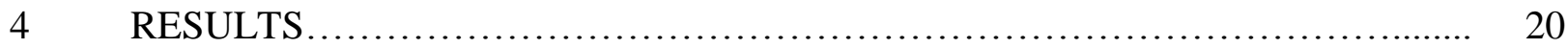

$4.1 \quad$ Rainfall Data................................................................... 20

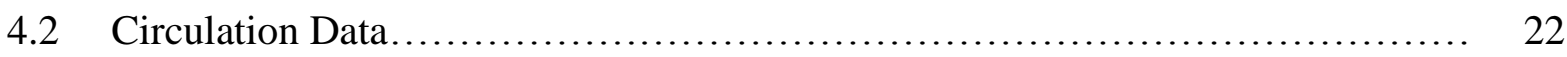

$4.3 \quad$ Moisture Transport Analysis.................................................... 23

$4.4 \quad$ Storm Track Analysis........................................................ 25

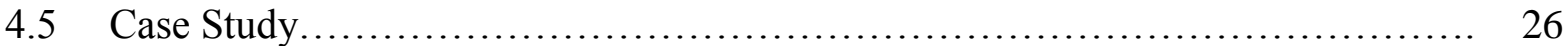

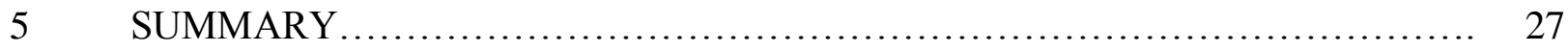

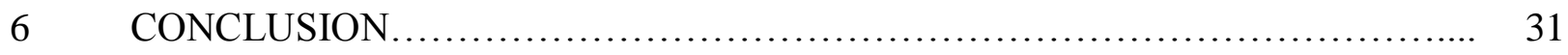

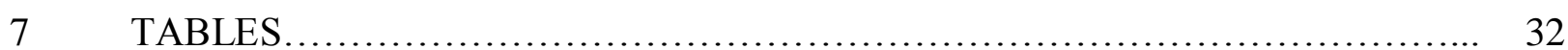

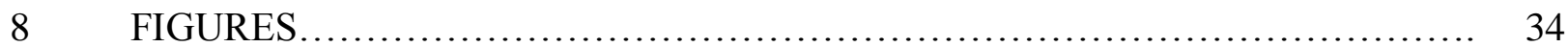

9 APPENDIX A: PETTITT-MANN-WHITNEY STATISTIC - A CHANGE-POINT

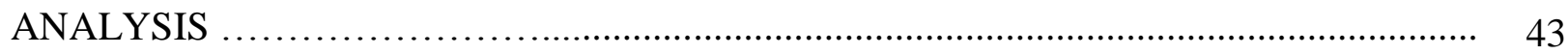

10 APPENDIX B: A CLASSICAL NONPARAMETRIC TEST FOR THE

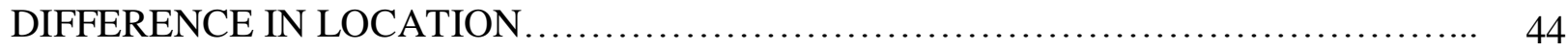

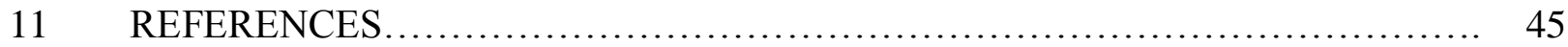




\section{LIST OF TABLES}

Table $1 \quad$ La Niña Events Used in Study........................................... 32

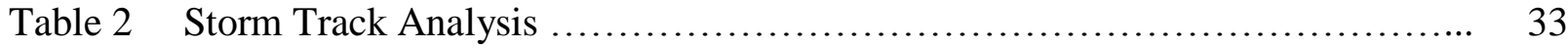




\section{LIST OF FIGURES}

Figure $1 \quad$ Orientation Map ............................................... 34

Figure 2 Standardized Rainfall Anomalies - Epoch Split........................ 35

Figure 3 Standardized Rainfall Anomalies - SST Split......................... 35

Figure 4 Rain Gauge Stations........................................... 36

Figure 5 Eastern North Pacific Subtropical High............................... 37

Figure 6 Lower Troposphere Winds....................................... 38

Figure $7 \quad$ North Pacific Subtropical Jet Stream................................. 39

Figure $8 \quad$ Moisture Flux................................................... 40

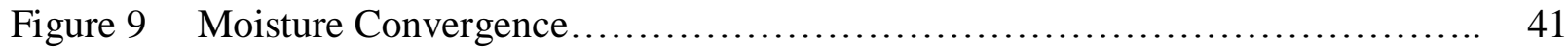

Figure 10 Case Study.................................................. 42 


\section{INTRODUCTION}

Pacific Island nations are small in size and are often isolated by a vast expanse of ocean. They are highly susceptible to natural disasters and extreme events, including tropical cyclones, droughts, floods and frequent inundation from high tides. Damages from such extreme events across this region are costly. For example, in the 1990s alone, costs from such instances are estimated to have exceeded US $\$ 1$ billion $(F A O, 2008)$. Many tropical Pacific islands are experiencing rapid population growth that places an increasing demand on water for drinking, food production, and other needs. Further compounding this problem is the great variability of interannual and interdecadal precipitation in this region. Hawai ' $\mathrm{i}$ in particular is vulnerable to extreme precipitation events resulting in flooding, and drought leading to lack of usable water and increased risk of fire (Chu et al., 2002). Proper planning for extreme events is essential to the well-being of these islands, which requires accurate information of year to year climate variability being made available to the governments and planners.

El Niño-Southern Oscillation (ENSO) is the leading mode of tropical atmosphere-ocean interaction on interannual time scales. Impacts from such events are felt throughout the entire planet (Trenberth and Caron, 2000). ENSO episodes are normally recognized through the observing of sea surface temperature (SST) anomalies in the equatorial Pacific region, most commonly in the Niño-3.4 region $\left(5^{\circ} \mathrm{S}-5^{\circ} \mathrm{N}, 120^{\circ}-170^{\circ} \mathrm{W}\right)$. The ENSO extremes are labeled as either a warm (El Niño) or cold (La Niña) phase, yet its amplitude varies across a continuum with essentially Gaussian statistics (Trenberth, 1997). Recent studies have made it apparent that the traditional definition of ENSO episodes is outdated, and fails to differentiate between two distinctive types of El Niño episodes. The first, being the canonical El Niño (EP El Niño), is centered in the eastern equatorial Pacific. More recently familiar is the El Niño (CP El Niño), 
centered farther west near the International Date Line. This CP type has also been referred to as the “central Pacific El Niño" (Yu and Kao, 2007) or "El Niño Mokodi” (Ashock et al., 2007), and its global impacts have gained increased interest (Hu et al., 2012). Also, potential increasing trends of CP events under global warming (Yeh et al., 2009) relative to those of the eastern Pacific El Niño are noteworthy.

Just as the distinction between EP and CP El Niño events is being made, Trenberth and Stepaniak (2001) support the notion that ENSO may come in many different "flavors" that are diverse from the canonical El Niño and La Niña composites. ENSO evidently cannot be characterized by a single index. These various ENSO "flavors" may contribute to climate variability and long-term trends in unique ways. Johnson (2012) presents a configuration that treats ENSO as a continuum but concludes a set maximum number of statistically distinguishable demonstrative ENSO patterns. They use a neural network-based cluster analysis called a selforganizing map (SOM) analysis, joined with a statistical distinguishability test, which determines nine unique patterns that characterize the September-February tropical Pacific SST anomaly patterns for the period from 1950 through 2011. These nine patterns represent the "flavors" of ENSO, which include EP, CP, mixed ENSO neutral patterns, and La Niña events. Over the 1950-2011 period, the most significant trends reflect changes in La Niña patterns. Weak or negative western Pacific warm pool SST anomalies dominate until the mid-1970s. This tendency is followed by a frequent occurrence of positive western Pacific warm pool SST anomalies during La Niña-like patterns, particularly after the mid-1990s. The current study considers the ENSO "flavors" concept and the shift of SST anomalies during more recent La Niña events to explore the effects of such occurrence on Hawai'ian precipitation. 
Large scale circulation mechanisms in the North Pacific have also undergone changes in recent decades. He and Gong (2002) found a decadal shift in the western North Pacific subtropical high occurring in about 1979/1980. Since 1980, the western North Pacific subtropical high has expanded, strengthened, and moved southwestward. This expansion has led to an increase of precipitation and has influenced significant warming in Southern China. The western North Pacific subtropical high responds considerably to SST of the tropical eastern Pacific with a lag time of one-two seasons, and concurrently with SST of the tropical Indian Ocean. The changes in the SST of the two above regions are mainly responsible for the interdecadal variability of the western North Pacific subtropical high. A similar relationship has been revealed in the current study, relating differing tropical western Pacific SST anomalies with simultaneous changes in the eastern North Pacific subtropical high.

Intensification of Northern Hemisphere summer subtropical highs has also occurred. In recent years, the North Atlantic subtropical high has been found to intensify, causing a westward movement of its western ridge in summer (Li et al., 2011). Over the western North Pacific, the western ridge of the North Pacific subtropical high has been observed to move westward significantly in summer ( $L u$ and Dong, 2001). Recent changes in the wintertime eastern North Pacific subtropical high, similar to those mentioned above in the western North Pacific subtropical high and the summertime North Hemisphere subtropical high, are revealed in this study.

In the synoptic-statistical approach to regional downscaling of seasonal rainfall in Hawai' $i$, Timm and Diaz (2006) present a few important arguments. They find that on the west side of Kaua'i, the wettest months experience a more relaxed eastern Pacific subtropical high pattern, and vice versa for drier months. In general, most areas of western Kaua'i receive a 
majority of their yearly precipitation during the wet season months from midlatitude storms. Therefore it can be drawn from their results that a weaker eastern Pacific subtropical high will promote favorable conditions for midlatitude systems to bring precipitation to these areas of the Hawai'ian Islands. Also presented is the relationship between meridional wind near the surface and precipitation in Hawai'i. An increase in precipitation throughout the islands is experienced when a southerly wind anomaly is present. The opposite can be said for a northerly wind anomaly, which yields a decrease in precipitation throughout the Hawai'ian region. These relationships are important to reference when considering the outcomes presented in the current study.

Winter jet streams over the Northern Hemisphere have undergone a transformation in recent decades. Strong and Davis (2007) studied trends in the speed of winter jet stream cores over the Northern Hemisphere from 1958-2007. Over the western and central Pacific, subtropical jet stream core speeds increased by as much as $1.75 \mathrm{~ms}^{-1}$ decade ${ }^{-1}$ in association with Hadley cell intensification. The subtropical jet also shifted poleward over the eastern Pacific. Only a modest change in the jet stream's strength or position can impact midlatitude storm tracks (Nakamura, 1992), as well as circulation regimes (Ruti et al., 2006). Chu and Chen (2005) reveal a correlation between the subtropical jet stream strength and position, and precipitation amounts in the Hawai'ian Islands. During El Niño years, the subtropical jet stream core strengthens and extends to the east, placing Hawai' $i$ closer to the right exit region of the jet, bringing increased subsidence and dryness to the islands of Hawai' $i$. The difference in subtropical jet stream strength and positioning during La Niña events, and its relation to rainfall in Hawai' $i$, has not been previously investigated and is explored in this study. 
The Hawai'ian Islands have two distinct seasons, a dry (warm) season and a wet (cool) season. The dry season is from May to October and is dominated by northeasterly trade winds (Garza et al., 2012; Norton et al., 2011) resulting from a quasi-stationary subtropical high to the northeast of the state. The main source of rainfall during this time is a result of the trade winds being orographically lifted by the mountainous regions of the islands to produce orographic precipitation systems. Tropical cyclones can also bring precipitation during the dry season; however extreme rainfall events resulting from tropical cyclones are quite rare to the island chain. The wet season extends from November to April. During this time, normal trade wind patterns are often interrupted by midlatitude fronts, Kona storms, and upper level disturbances (Ramage, 1962; Schroeder, 1993). These events cause increased precipitation during the wet season, and are quite capable of bringing extreme precipitation to the region. An investigation of the Hawai'ian Rainfall Index (Chu et al., 2010) shows an interesting trend in the year round precipitation amounts. Since 1980, a strong negative trend indicates a decrease of overall rainfall in the state of Hawai'i.

ENSO is of most concern for rainfall variability in the tropical Pacific Islands (Ropelewski and Halpert, 1987). The winter season is usually when impacts from ENSO are most likely to be realized (Kruk et al., 2014). Hawai'i commonly experiences drier than normal conditions during El Niño wet seasons, and greater than normal precipitation during the wet season of La Niña years. More specifically, small and positive rainfall amounts are noted from July to October during the El Niño developing years. Deficient rainfall then persists for six consecutive months from November to April of the following year, with a large negative anomaly in January and February $(C h u, 1995)$. Traditionally, rainfall variations during La Niña 
events are opposite to that of El Niño, while the largest positive anomaly also occurs in January and February (Chu and Chen, 2005).

However, over the last three decades, Hawai' $i$ has experienced drier conditions during the wet season (November to April) of La Niña years. The objective of this study is to examine changes of the precipitation in Hawai 'i during La Niña events since 1956, and to reveal possible explanation as it's the cause. Section 2 describes observational, reanalysis, and GPCP data. In section 3, the methodology for the study is discussed. Section 4 discusses the results from the comparison of rainfall station data between 1956-1982 (Epoch 1) and 1983-2010 (Epoch 2) and negative/positive western North Pacific warm pool SST anomalies, evaluates the circulation features of both epochs, presents a moisture transport analysis, implements a storm track analysis, and explores large-scale winter precipitation patterns in the Pacific from two La Niña events. A summary is found in section 5, followed by section 6 , which depicts the conclusion. 


\section{DATA}

\subsection{Time Period}

This study focuses solely on La Niña events, and therefore considers data from these years exclusively. It is well known that the Hawai'ian Islands have two different seasons, a dry/warm season (May to October) and a wet/cold season (November to April). Since the impacts from ENSO are most likely to be realized during the wet season, and the major rainfall-bearing weather systems in Hawai'i are prevalent during the wet season, this study only examines data from this portion of the year (November to April). The length of study is determined to be 19562010 (55 years). The first year in the study is established as 1956 for the reason that there is inconsistency in the completeness of the rainfall station data leading up to this year. Prior to 1956, a number of important stations contain large amounts of missing data and would be excluded. In order to hold the wet season data intact, the water year is defined from July to June of the subsequent year. For example, 1956 means from July 1956 to June 1957, while the 1956 wet season means from November 1956 to April 1957. Based on a change-point analysis to be shown later, it is found that a significant shift has occurred during 1983 in Hawai'ian precipitation. Therefore the time period is split into two epochs, known as Epoch 1 (E1 [19561982, 27 years]) and Epoch 2 (E2 [1983-2010, 28 years]), to investigate the possible influencers of precipitation change.

\subsection{Oceanic Niño Index (ONI)}

La Niña events are determined using the Oceanic Niño Index (ONI), from the National Weather Service (NWS) Climate Prediction Center (CPC). Warm (El Niño) and cold (La Niña) episodes are established on a threshold of $+/-0.5$ degrees Celsius for the ONI. This is a three month running mean of ERSST.v3b SST anomalies in the Niño 3.4 region. The anomalies are 
centered on 30-year base periods updated every five years. Cold and warm episodes are defined when the threshold is met for a minimum of five consecutive over-lapping seasons. Table 1 lists all La Niña events used in this study.

\subsection{Rainfall Gauge Data}

Monthly precipitation data (TD3220) of cooperative (COOP) stations are obtained from the National Oceanic and Atmospheric Administration (NOAA)/National Climatic Data Center (NCDC). Rainfall data from 50 stations with best continuity are collected, differing in elevation and location (leeward, windward), on the four main islands in the state (Kaua'i, Oahu, Maui, and Hawai'i). The orientation map of the Hawai'ian Islands is shown in Figure 1. Because of the high mountains and steep terrains in Hawai'i, dissimilar locations of rain gauge stations are desirable to ensure micro-climates [Dolling et al., 2009] be well represented, by avoiding location dependent bias in the study.

\subsection{Circulation Data}

National Centers for Environmental Prediction (NCEP) reanalysis I monthly mean data, from the Earth System Research Laboratory (ESRL)/NOAA, are gathered to perform circulation analysis in the North Pacific region. The dataset consists of atmospheric variables at 8 different pressure levels $(1000 \mathrm{hPa}$ to $300 \mathrm{hPa})$, at a resolution of 2.5 degree latitude $\mathrm{x} 2.5$ degree longitude on a global grid. Individual variables include: geopotential height, sea level pressure, specific humidity, and wind. Reanalysis I data, extending back to 1948, are preferred over the reanalysis II data because its length of record is more suitable for this 55 year climatic study. While the reanalysis II data have shown better representation of winter time circulation when compared to reanalysis I data [Kanamitsu et al., 2002], it only extends back to 1981, and is therefore undesirable for this study. 


\subsection{Global Precipitation Data}

Global Precipitation Climatology Project (GPCP) precipitation data are used, provided by the NOAA/OAR/ESRL Physical Sciences Division (PSD), Boulder, Colorado, USA, from their Web site at http://www.esrl.noaa.gov/psd/. The GPCP combined precipitation data are developed and computed by the NASA/Goddard Space Flight Center's Laboratory for Atmospheres as a contribution to the GEWEX Global Precipitation Climatology Project. This data set consists of monthly means of precipitation derived from satellite and gauge measurements. Much like the reanalysis dataset, GPCP data has a coarse resolution of 2.5 degree latitude x 2.5 degree longitude on a global grid. Therefore, instead of using GPCP data to investigate area specific rainfall tendencies in Hawai'i, GPCP data are employed simply to reveal precipitation characteristics in the broader vicinity of the islands. Being that the data only extends back to 1979, it is not possible to explore precipitation differences between epochs; however the GPCP data is useful in examining differences in precipitation between La Niña flavors. 


\section{METHODOLOGY}

\subsection{Normalized Rainfall Data}

All rain gauge data at each individual station are transformed into a standardized anomaly form according to

$$
\text { standardized anomaly }=\frac{x-\bar{x}}{s}
$$

where $x$ is the seasonal rainfall amount for a particular year, $\bar{x}$ is the seasonal mean, and $s$ is the seasonal standard deviation [Junker et al., 2007]. This transformation ensures that the resultant precipitation series will be dimensionless. Thus the series holds a mean of zero and a standard deviation of one, so the variation on wet windward stations is comparable to dry leeward locations. Calculated standardized anomalies from all 50 stations are averaged for each year. These averaged anomalies, approximately following a Gaussian distribution, are then plotted to detect trends in the precipitation time series. For qualification purposes, the Gaussian distribution is divided into three terciles. According to the standard Gaussian distribution, an anomaly with $Z \leq-0.43$ is in the bottom tercile of the distribution. For this study, a standardized rainfall anomaly falling in the bottom tercile is considered a drier than normal year. A standardized rainfall anomaly with $Z \geq 0.43$ is in the top tercile of the distribution, and is considered a wetter than normal year. Any anomaly standing in the $-0.43 \leq Z \leq 0.43$ is considered to be a normal precipitation year. Junker et al. (2007) used the standardized anomalies to anticipate extreme rainfall in the mountains of northern California.

As previously described in the Introduction section, during 1950-2011, Johnson (2012) indicated nine individual SST "flavors" in the equatorial Pacific. Of these nine unique SST patterns, La Niña events occur during five. Flavors 1, 2, and 5 exhibit negative western 
equatorial Pacific warm pool SST anomalies (NA), while flavors 3 and 4 reveal positive western equatorial Pacific warm pool SST anomalies (PA). The normalized rainfall data from this study are plotted according to the two different western Pacific SST anomaly patterns, NA and PA, in order to reveal the influence of such SST anomaly patterns on Hawai'ian precipitation during La Niña events.

Changes in the rainfall data at each individual station throughout the Hawai'ian Islands are also considered. The anomalies are averaged for each epoch, resulting in an E1 and E2 average anomaly value for each station. The difference between E1 and E2 is calculated at each respective location in order to study the changes of rainfall at each station. To classify the magnitude of the change in precipitation, a scale has been established. A difference greater than 0.6 (or less than -0.6) is considered as a strong change. A moderate change is classified as a difference between 0.3 and 0.6 . Slight change is categorized between 0.05 and 0.3 , while no change is a difference less than 0.05 .

\subsection{Change-Point Detection Method and Hypothesis Testing}

The Pettitt-Mann-Whitney statistic, described fully in Appendix A, is used for determining the year of change in time series. Nazemosadat et al. [2006] applied this test for investigating climate change in Iran as signified by the change in precipitation data. The changepoint analysis is also utilized by Bassiouni and Oki [2012] to detect a downward shift in streamflow in Hawai' $i$ during the $20^{\text {th }}$ century. The most significant change-point is found where the significance probability $P(t)$ (Eq. A5) reaches a maximum. Using the normalized rainfall data $P(t)$ is found to be at a maximum in $1983(P(t)=0.94)$, indicating a significant shift has occurred in Hawai'ian precipitation in 1983. Therefore, the first epoch runs from 1956 to 1982 (E1) and the second epoch is from 1983 to 2010 (E2). 
To compare the significance of the difference in the data found between Epoch 1 and Epoch 2, a nonparametric statistical test called the Wilcoxon-Mann-Whitney test is implemented. This test is described in Appendix B.

\subsection{Reanalysis Data}

NCEP Reanalysis I data are used to compare climatological variables (geopotential height, sea level pressure, specific humidity, and wind) during both epochs. For each climatological variable, the difference between the two epochs is calculated $(E 2-E 1)$ in an attempt to discover causes for the recent drying trend during La Niña wet seasons in Hawai'i. Results are plotted and compared using the Grid Analysis and Display System (GrADS).

\subsection{Moisture Transport Analysis}

To address what contributes to the decrease of rainfall during recent La Niña years (Epoch 2), a column-integrated moisture transport analysis is performed. Following Hsu et al., [2012], the total moisture flux is calculated to compare the relative contribution of moisture convergence and advection using

$$
-\Delta<\nabla \cdot(q \boldsymbol{V})>=-\Delta<q(\nabla \cdot \boldsymbol{V})>-\Delta<\boldsymbol{V} \cdot(\nabla q)>
$$

where $q$ is specific humidity, $\boldsymbol{V}$ is the horizontal vector wind, $<>$ indicates a vertical integration from 1000 to $300 \mathrm{hPa}$, and $\nabla$ is the horizontal gradient operator. The operator $\Delta$ represents the difference between Epoch 2 and Epoch 1 (E2 minus E1). Specific humidity $q$ is defined as the ratio of water vapor mass $(g)$ over air mass $(k g)$, which holds units $g \mathrm{~kg}^{-1} . \boldsymbol{V}$ is horizontal wind

$(u, v)$, which holds units $m s^{-1}$. The first term on the right hand side of Eq. 2 is the moisture convergence term, while the second term is the moisture advection term. Moisture convergence 
denotes the product of the specific humidity and horizontal mass convergence $\left(m^{2} s^{-1}\right)$. The advection term represents the horizontal advection of specific humidity $\left(\mathrm{m}^{2} \mathrm{~s}^{-1}\right)$ by winds.

In the total moisture flux, the change in moisture convergence is found to be one order of magnitude larger than the change in moisture advection. Thus the following equation is used to further examine the role of the dynamic and thermodynamic effect in contributing to moisture convergence change in the Hawai'ian region,

$$
-\Delta<q * D>=-<q * \Delta D>-<\Delta q * D>-<\Delta \mathrm{q} * \Delta D>
$$

where $D$ is divergence $\left(m^{2} s^{-1}\right)$. The first term on the right-hand side of Eq. 3 is associated with the circulation change, which may be regarded as a dynamic contributor. The second term involves the change of water vapor content, thus it reflects the thermodynamic effect. The third term is a nonlinear term including the effect of both the moisture and circulation changes.

\subsection{Storm Track Analysis}

After the circulation patterns are studied, a storm track analysis is performed in order to quantifiably measure the contribution of mean circulation changes towards the alteration of specific weather phenomenon between epochs. As stated in the Introduction section, midlatitude fronts, Kona lows, and upper level lows are the three main precipitation bearing systems to the Hawai'ian Islands. Outputs of sea level pressure, and geopotential height at $500 \mathrm{hPa}$ and 250 $\mathrm{hPa}$, are analyzed at each daily time step to identify individual systems which potentially bring rainfall to the islands. A storm count is then computed and epoch differences are compared.

A certain criterion is established to achieve this storm count. Systems that reach a predetermined area of study $\left(18.5^{\circ} \mathrm{N}-22.5^{\circ} \mathrm{N}, 159.5^{\circ} \mathrm{W}-154.5^{\circ} \mathrm{W}\right.$ [Fig.1]) are counted and 
summed for each La Niña winter. Low pressure must show a cut-off signature to be considered a Kona low or an upper-level low. In attempt to accurately identify Kona lows, previous relevant literature is investigated (Otkin and Martin, 2004; Caruso and Businger, 2006). The following precedent is established: a system is considered to be a Kona low formation when the disturbance shows a complete cut-off signature at the surface, as well as in the upper troposphere. Upper-level disturbances without a cut-off formation are not counted in this analysis. Often a midlatitude front produces a shear line, which can extend to the Hawai'i. When a shear line enters the study region, it is tallied as a midlatitude front in the storm count. Disturbances that do not enter the area of Hawai' $\mathrm{i}$ are not considered. 


\section{$4 \quad$ RESULTS}

\subsection{Rainfall Data}

The standardized rainfall anomalies for the two epochs are shown in Figure 2, displaying a drying trend in Hawai'ian rainfall during the wet seasons of La Niña years since 1956. The change since 1983 is particularly pronounced. According to the guidelines mentioned in the Methodology section, all precipitation anomalies in La Niña years are categorized as either normal $(-0.43 \leq Z \leq 0.43)$, drier than normal $(Z \leq-0.43)$, or wetter than normal $(Z \geq 0.43)$. During Epoch 1, positive rainfall anomalies $(Z>0)$ dominate during Epoch 1 (seven of seven occurrences). Almost half of the standardized rainfall anomalies are wetter than normal (three of seven occurrences), while the other four are near normal. However, in the second epoch, only $18 \%$ of rainfall anomalies are wetter than normal (two of 11 occurrences), while $27 \%$ of rainfall anomalies are drier than normal (three of 11 occurrences). Of the normal rainfall anomalies (six of 11 occurrences) during E2, three have a positive standardized anomaly, while the other three score negative values. While the results presented in Figure 2 reveal qualitatively a shift of La Niña rainfall, the Wilcoxon-Mann-Whitney rank sum test is performed to test the statistical significance of the shift. The resulting p-value of $1.26 \%$ suggests that there is a strong significant difference in La Niña rainfall between E1 and E2.

Rainfall data are further examined by splitting the dataset into equatorial western Pacific SST anomaly patterns, NA and PA. NA patterns dominate in the early portion of the study until about the mid-1980s, after which PA anomalies prevail. The wettest La Niña season in this study (1988/89), in terms of the average normalized rainfall data, is characterized by NA anomalies. A strong relationship exists between NA (PA) anomalies and greater (less) than normal Hawai'ian rainfall. Figure 3 reveals the NA anomalies lead to positive rainfall anomalies in Hawai' 1 nine 
out of nine occurrences. More than half of these standardized rainfall anomalies are in the upper tercile (five of nine occurrences: $55.6 \%$ ), while the other $44.4 \%$ are near normal. Conversely, during PA La Niña events, only $11.1 \%$ of rainfall anomalies are wetter than normal (one of nine occurrences), while $33.3 \%$ of rainfall anomalies are drier than normal (three of nine occurrences). Of the near normal rainfall anomalies (5 of 9 occurrences) during La Niña years with PA anomalies, only two have a positive standardized anomaly, whereas three score negative values. The nonparametric rank sum test is performed to test the statistical significance of the shift. The resulting p-value of $0.09 \%$ implies that there is an extremely strong and significant difference in Hawai'ian La Niña rainfall anomalies between positive and negative western Pacific equatorial SST anomaly patterns.

Location dependent changes of the rainfall data in the Hawai'ian Islands are explored. Figure 4 displays the relative rainfall differences between E1 and E2 at each of the 50 stations used in this study, as well as the results from the nonparametric significance testing. Decreasing rainfall is highly prominent at all island locations; however a deeper understanding is gained by observing inter-island differences. For this analysis, the determined strength of the difference in precipitation is determined by the scale set in the Methodology section, and is displayed in the legend of Figure 4. Kaua'i shows a substantial negative difference in rainfall throughout the island (eight of 13 stations reveal strong decrease). The most outstanding decrease is found in the rainfall stations on the island of Oahu. 10 of the 14 stations experience a strong negative difference, all of which are significant at the $10 \%$ level ( 8 are significant at the $5 \%$ level). On the other hand, the island of Maui shows the least decrease in rainfall of all islands. None of the Maui stations reveal strong decrease, while four of the 11 stations show moderate decrease, and seven stations express weak decrease. Only one of the rain gauge locations on Maui shows 
significant change at the $10 \%$ level (Kahului Airport). The island of Hawai'i displays a strong decrease of rainfall in seven of 12 stations, while changes in five of the stations are statistically significant at the 5\% level. Only one station in all of the state shows an increase in rainfall, and happens to be on the NE side of the island of Hawai' ${ }^{\text {i }}$. Interesting to note from this comparison, the areas where most extreme difference in rainfall is experienced between the two epochs are climatologically drier areas, mostly on the southern and western sides of the islands. These areas, particularly on Kaua'i and Oahu, receive most of their rainfall during the wet season from extratropical precipitation producing events.

\subsection{Circulation Data}

An examination of NCEP Reanalysis I circulation data reveals a few intriguing characteristics that potentially lead to a drying trend in Hawai'i from Epoch 1 to 2 . There are two circulation features that are outstanding during the entire analysis period: the eastern North Pacific subtropical ridge, and the North Pacific subtropical jet stream.

Seasonal mean geopotential height $(m)$ at $850 \mathrm{hPa}$ is presented in Figure 5, which shows a good signature of the eastern North Pacific subtropical ridge as represented by the contour of $1540 \mathrm{~m}$. Comparing Figure 5a with Figure 5b, an elongation and strengthening of the subtropical ridge occurs during Epoch 2. In the region to the north of Hawai 'i, the ridge line stretches westward to approximately $165^{\circ} \mathrm{W}$ during Epoch 2 , just to the north of Hawai' $\mathrm{i}$ (Fig. 5b), where during Epoch 1 the ridge line retreats eastward at $150^{\circ} \mathrm{W}$. Displaying the difference between E1 and E2, Figure 5c shows an increase in geopotential height over Hawai ${ }^{\prime} i$, the subtropical eastern North Pacific, and the western U.S. during Epoch 2. A center of maximum difference in geopotential height is found near Hawai $i$. The change in geopotential height between the two epochs is significantly different at a $95 \%$ confidence level over the aforementioned regions. 
Seasonal mean wind $\left(m s^{-1}\right)$ in the lower troposphere $(925 \mathrm{hPa})$ throughout the Hawai'ian region experiences a change due to the variation of the subtropical ridge, as shown in Figure 6. During Epoch 1 the wind over Hawai' $i$ is characterized by the east-southeast direction (Fig. 6a). The southerly component is lost during Epoch 2, as the wind direction over Hawai' $\mathrm{i}$ is mainly easterly (Fig. 6b). A southerly tilt in the wind tends to bring an increase in moisture from the south to the state. Therefore it is expected that the shifting seasonal mean wind direction in Epoch 2, influenced by the elongation of the subtropical ridge, provides the Hawai'ian region with less available moisture from the tropics for precipitation events.

Observing circulation in the upper troposphere $(200 \mathrm{hPa})$, seasonal mean zonal wind $\left(m s^{-1}\right)$ displayed in Figure 7 indicates a strengthening and extending of the subtropical jet stream core to the east during the second epoch. The easternmost section of the $40 \mathrm{~m} \mathrm{~s}^{-1}$ contour touches $178^{\circ} \mathrm{W}$ in Epoch 1 (Fig. 7a), whereas in Epoch 2 (Fig. 7b) the same contour line extends to $170^{\circ} \mathrm{W}$. Similarly, the $60 \mathrm{~m} \mathrm{~s}^{-1}$ contour experiences a substantial increase in its E-W radius and overall circumference throughout E2. Chu (1995) noted an extension of the North Pacific subtropical jet occurring during El Niño winters, which inhibits wintertime rainfall production in Hawai' $i$. Figure 7c shows the difference in seasonal mean zonal wind between the two epochs. The elongation of the subtropical jet during the second epoch is confirmed as significant at a $95 \%$ confidence level. This extension of the jet experienced during E2 places Hawai' $i$ closer to the right exit region of the jet, bringing increased subsidence and dryness to the region.

\subsection{Moisture Transport Analysis}

A column-integrated moisture transport analysis is shown in Figure 8. Investigation of the seasonal mean total moisture flux reveals moisture convergence in the tropical region 
(equatorward of $15^{\circ} \mathrm{N}$ ), in the midlatitude storm track area, and in the region north of Hawai' $\mathrm{i}$ (Figs. 8a and b). Moisture divergence is prevalent in most of the subtropical Pacific and in the region SW of Hawai'i. The difference in moisture flux between the two epochs is shown in Figure 8c. As anticipated, there is a decrease of moisture convergence in the region to the north of Hawai'i. An increase of moisture divergence is seen in the region to the SE of Hawai' $i$ and in most of the Central Pacific subtropical region during Epoch 2.

From the total moisture flux equation (Eq. 2), the change between epochs in the moisture convergence term is found to be larger than that in moisture advection term. As a result the moisture convergence term is broken down (Eq. 3) to examine the role of the dynamic effect (i.e. circulation), the thermodynamic effect (i.e. water vapor content), and the non-linear effect (i.e. combined influence of moisture and circulation) in contributing to moisture change throughout the Hawai'ian region. Because attention is on the area surrounding the Islands of Hawai' $i$, the moisture convergence analysis is performed for a smaller region bounded by $170^{\circ} \mathrm{W}-140^{\circ} \mathrm{W}$, $15^{\circ} \mathrm{N}-30^{\circ} \mathrm{N}$. While the changes are subtle between epochs, concern is focused on the area average difference in magnitude. Figure 9 represents the difference between epochs of the three effects described above. In the Hawai'ian region, the area averaged change in circulation between epochs is one order of magnitude greater than the difference revealed in the water vapor content, and two orders of magnitude greater than the change presented in the combined influence of moisture and circulation. In conclusion, the difference in the dynamic effect between epochs is the primary contributor to the change in moisture transport surrounding Hawai'i throughout E2. 


\subsection{Storm Track Analysis}

In order to consider the influence of circulation differences between epochs on the individual storms promoting Hawai'ian precipitation, a storm track analysis is performed. Results from the analysis are laid out in Table 2. Generally speaking, each of the three main precipitation bearing systems occurs at a lower rate during Epoch 2. An E2/E1 ratio is calculated for each storm type to weigh the magnitude of decrease. Kona lows feel the greatest scaled decrease, as Epoch 2 yields 44\% less Kona lows when compared to Epoch 1. While not quite as extreme, midlatitude fronts experience a 23\% decrease during Epoch 2. Upper-level lows see the smallest difference in occurrence between epochs, yielding an $18 \%$ decrease during the second epoch.

The nonparametric rank sum test is performed on all three datasets, revealing a statistically significant difference in Kona lows $(Z=0.056)$ and midlatitude fronts $(Z=0.056)$ between epochs at a 94\% confidence level. The change in upper-level lows does not prove to be statistically significant $(Z=0.446)$ according to the rank sum test. Therefore it can be assumed that the enlarging and westward shifting of the eastern Pacific subtropical high, as well as the strengthening and extending of the North Pacific subtropical jet stream during the second epoch, provides less favorable conditions for the development of Kona lows and midlatitude storms in the Hawai'ian region. The expansion of the eastern Pacific subtropical high during E2 acts as a blocking mechanism for midlatitude storms and shear lines, inhibiting these systems from reaching Hawai'i. The westward shifting of the eastern Pacific subtropical high also inhibits the surface low formation in the Hawai'ian region necessary for Kona low development. While the upper-level lows do see an average annual decrease during Epoch 2, these systems do not succumb to such drastic influence. 


\subsection{Case Study}

Because of the shorter duration of GPCP Data, it is impossible to compare these data using the epoch splitting method used throughout this study. However, two case studies are performed investigating precipitation throughout the North Pacific during a dry $(Z=-0.93) \mathrm{La}$ Niña event (1983-1984) and a very wet $(Z=1.70)$ La Niña year (1988-1989) in Hawai'i. Figure 10a illustrates the dry occasion, where a zonal band of very low precipitation is experienced throughout most of the subtropics in the North Pacific, producing a mean precipitation rate ranging from one to three $m m d a y^{-1}$. The wet case displayed in Figure $10 \mathrm{~b}$ reveals a large area of increased precipitation in the subtropical Central Pacific. During this time, mean precipitation rates span from three to seven $m m d^{-1} a y^{-1}$ in the Hawai'ian region. For reference, the 1988-1989 La Niña event was the wettest episode of all the La Niña years in the study.

Through study of the eastern Pacific subtropical high and the North Pacific subtropical jet stream during these two La Niña events, the case study provides further evidence towards the current research as a whole. During the 1988-1989 wet La Niña event, the westernmost point of the $1540 \mathrm{~m}$ contour from the eastern Pacific subtropical high rests at $162^{\circ} \mathrm{W}$ and $28^{\circ} \mathrm{N}$. In the 1983-1984 dry La Niña event, this same contour line stretches to $173^{\circ} \mathrm{W}$ and extends as far south to $21.5^{\circ} \mathrm{N}$, so that the high pressure system almost completely covers the Hawai ian Islands. While considering the North Pacific subtropical jet during the wet event (88-89), the easternmost section of the $40 \mathrm{~m} \mathrm{~s}^{-1}$ contour touches $178^{\circ} \mathrm{W}$. During the dry event (83-84) this equivalent contour extends to $160^{\circ} \mathrm{W}$, which is directly to the north of the island of Kaua 'i, and places the Hawai'ian Islands much closer to the right exit region of the jet. This case study analysis validates the relationship between circulation features and rainfall anomalies, which has been proposed throughout the paper. 


\section{SUMMARY}

On an interannual time scale, La Niña events are perceived to bring greater than normal seasonal mean precipitation to the Hawai'ian Islands during the wet season. However since the early 1980’s, Hawai'i has experienced a drying trend in precipitation during La Niña winters. Investigation of recent ENSO literature reveals a change in SST patterns in the equatorial western Pacific warm pool during recent La Niña years, which may play an important role in the shift of precipitation patterns in the Islands of Hawai 'i. Location dependent changes of the rainfall data in the Hawai'ian Islands are also explored. Additional research has exposed adjustments in circulation features in the Pacific since the early 1980's, including an expansion of the western North Pacific subtropical high due to changes in the sea surface temperatures (He and Gong, 2002). Also, Strong and Davis (2007) have shown that since 1958 subtropical jet stream core speeds over the western and central North Pacific have increased by as much as 1.75 $m s^{-1}$ per decade in association with Hadley cell intensification. The aim of this current study is to reveal the possible causes for the shift in Hawai' 'ian precipitation during La Niña winters over the last few decades.

This study is based on observational rainfall station data on the four major islands (Hawai ${ }^{`} i$, Maui, Oahu, Kaua'i), NCEP reanalysis I data, and GPCP data. All rain gauge data are transformed into a standardized anomaly form at each individual station. The Pettitt-MannWhitney statistic is used for determining 1983 as the change-point year in the seasonal rainfall time series (November - April). For each climatological variable, such as geopotential height, the difference between the two epochs is calculated $(E 2-E 1)$. To compare the significance of the difference in data samples found between Epoch 1 and Epoch 2, a nonparametric statistical test is implemented on the rainfall data as well as the reanalysis datasets. A column-integrated 
moisture transport analysis is performed to address changes in circulation and moisture advection between epochs. The moisture convergence equation is further considered to examine the role of the circulation and water vapor content in contributing to the significant moisture convergence contrast in the Hawai'ian region.

A comparison of the standardized rainfall anomalies for the two epochs reveals a drying trend in Hawai'ian rainfall during the wet seasons of La Niña years since 1956, while the nonparametric testing of the data reveals statistical significance in the rainfall index between the two epochs at the 5\% level. Normalized rainfall data is further examined by splitting the dataset into SST anomaly patterns, revealing a well-defined connection between negative (positive) SST anomalies in the western Pacific warm pool and positive (negative) rainfall anomalies in Hawai'i. The nonparametric test reveals that there is an extremely strong and significant difference in La Niña rainfall between PA and NA anomaly patterns. An assessment of location dependent differences in Hawai'ian rainfall station data reveals a noteworthy outcome. The areas exuding greatest alteration in rainfall are climatologically drier areas on the southern and western sides of the islands. These zones, particularly on Kaua'i and Oahu, receive most of their rainfall during the wet season from midlatitude disturbances.

Examination of NCEP Reanalysis I circulation data exposes a few intriguing characteristics, potentially acting as contributors to the drying trend in Hawai'i during Epoch 2. The eastern North Pacific subtropical ridge and the North Pacific subtropical jet stream are two circulation features that display alteration. Evaluating seasonal mean geopotential height $(m)$ at $850 \mathrm{hPa}$ exposes an elongation and strengthening of the subtropical ridge occurring during Epoch 2. Seasonal mean wind $\left(m^{-1}\right)$ near the surface $(925 \mathrm{hPa})$ in the Hawai'ian region experiences a change due to the variation of the subtropical ridge, with wind direction shifting 
from east-southeasterly in E1 to easterly in E2. This shift in wind direction influences a consequence of less total water substance present, as moisture laden air to the south of Hawai' $\mathrm{i}$ is more restricted from reaching the islands. The seasonal mean zonal wind $\left(m s^{-1}\right)$ in the upper troposphere indicates a strengthening and extending of the subtropical jet stream to $174^{\circ} \mathrm{W}$ during the second epoch. This stretching positions Hawai 'i closer to the right exit region of the jet, which is recognized to promote dryness.

A column-integrated moisture transport analysis reveals a decrease of moisture convergence in the region to the north of Hawai' $i$ in the most recent epoch. An increase of moisture divergence is seen in the region to the SE of Hawai' $i$ and in most of the Central Pacific subtropical region during Epoch 2. Discovering that the convergence term in Eq. 2 is the main influencer to this difference in moisture flux, this term is further investigated to examine the role of the dynamic effect, the thermodynamic effect, and the non-linear effect in contribution. The change in the circulation between epochs is found to be the primary contributor to the difference in moisture surrounding Hawai'i throughout E2.

Influence from circulation changes on individual precipitation producing systems is considered using a storm track analysis. Individual midlatitude fronts, Kona lows, and upperlevel lows, which enter the Hawai'ian region, are counted and totaled for each La Niña wet season. Results advocate that Kona lows and midlatitude fronts feel the most drastic change during Epoch 2, and such epoch differences are suggested to be statistically significant. Upperlevel lows do not experience such an extreme change between epochs. Therefore it can be assumed that the declining occurrence of Kona lows and midlatitude fronts proves to be the main influence for a decrease in precipitation since 1983 throughout the Hawai'ian region. This roughly constructed storm track comparison can be enhanced by following a model similar to 
that presented by Zhang et al. (2004) in their work concerning the climatology and interannual variability of artic cyclone tracks. Furthermore, a case study is performed, providing additional support towards the influence of large-scale circulation features on Hawai'ian winter rainfall during La Niña events. 


\section{CONCLUSION}

The results presented in this study may benefit many agencies who are concerned with forecasting precipitation for Hawai'i winter seasons during La Niña events. For instance, the National Weather Service of Honolulu produces seasonal precipitation predictions for the Islands of Hawai'i. Because many people, such as farmers, hydrologists or city and county planners, rely on these projections, improving the accuracy of such predictions is vital to the well-being of Hawai'ian citizens. Also, because the La Niña events are believed to bring excess rainfall to the state, the lesser known possibility of decreased rainfall during these events must be publicized so that proper planning and hydrological management can ensue. Such information proves to be highly valuable for any tropical Pacific island community which may be feeling similar changes

in seasonal rainfall trends. The method performed in this study can be implemented for any specific area in order to maintain an accurate depiction of possible rainfall climates per season, especially those which have experienced a change in precipitation during recent La Niña events. 


\section{TABLES}

7.1 Table 1: La Niña Events Used In Study

\begin{tabular}{ccc}
\hline La Niña Wet Seasons & Epoch & WEPA \\
\hline 1956 & 1 & NA \\
$\mathbf{1 9 6 4}$ & 1 & NA \\
1970 & 1 & NA \\
1971 & 1 & NA \\
1973 & 1 & NA \\
1974 & 1 & NA \\
1975 & 1 & NA \\
1983 & 2 & PA \\
$\mathbf{1 9 8 4}$ & 2 & NA \\
$\mathbf{1 9 8 8}$ & 2 & NA \\
$\mathbf{1 9 9 5}$ & 2 & PA \\
$\mathbf{1 9 9 8}$ & 2 & PA \\
$\mathbf{1 9 9 9}$ & 2 & PA \\
$\mathbf{2 0 0 0}$ & 2 & PA \\
$\mathbf{2 0 0 5}$ & 2 & PA \\
$\mathbf{2 0 0 7}$ & 2 & PA \\
$\mathbf{2 0 0 8}$ & 2 & PA \\
$\mathbf{2 0 1 0}$ & 2 & PA \\
\hline
\end{tabular}

Table 1: WEPA standing for western equatorial Pacific SST anomaly throughout the La Niña event, NA (PA) for negative (positive) anomalies. 
7.2 Table 2: Storm Track Analysis

\begin{tabular}{ccccc}
\hline $\begin{array}{c}\text { La Niña } \\
\text { Wet Seasons }\end{array}$ & Midlatitude Storms & Kona Lows & Upper-level Lows & Rainfall Anomaly \\
\hline $\mathbf{1 9 5 6}$ & 15 & 3 & 2 & 0.16 \\
$\mathbf{1 9 6 4}$ & 18 & 5 & 2 & 0.50 \\
$\mathbf{1 9 7 0}$ & 11 & 6 & 8 & 1.26 \\
$\mathbf{1 9 7 1}$ & 9 & 10 & 3 & 0.21 \\
$\mathbf{1 9 7 3}$ & 17 & 5 & 7 & 0.90 \\
$\mathbf{1 9 7 4}$ & 9 & 4 & 6 & 0.23 \\
$\mathbf{1 9 7 5}$ & 14 & 5 & 6 & -0.93 \\
\hline $\mathbf{1 9 8 3}$ & 11 & 2 & 1 & 0.06 \\
$\mathbf{1 9 8 4}$ & 13 & 5 & 4 & 1.70 \\
$\mathbf{1 9 8 8}$ & 14 & 3 & 2 & -0.02 \\
$\mathbf{1 9 9 5}$ & 12 & 4 & 3 & -0.39 \\
$\mathbf{1 9 9 8}$ & 8 & 1 & 4 & -0.81 \\
$\mathbf{1 9 9 9}$ & 6 & 1 & 4 & -0.83 \\
$\mathbf{2 0 0 0}$ & 10 & 1 & 2 & 0.53 \\
$\mathbf{2 0 0 5}$ & 8 & 4 & 6 & 0.06 \\
$\mathbf{2 0 0 7}$ & 12 & 3 & 6 & -0.11 \\
\hline $\mathbf{2 0 0 8}$ & 8 & 5 & 5 & 0.14 \\
\hline $\mathbf{2 0 1 0}$ & 10 & 4 & 7 & - \\
\hline E1 AVG & $\mathbf{1 3 . 3}$ & $\mathbf{5 . 4}$ & $\mathbf{4 . 9}$ & - \\
\hline E2 AVG & $\mathbf{1 0 . 2}$ & $\mathbf{3 . 0}$ & $\mathbf{4 . 0}$ & - \\
\hline (E2 - E1) & $\mathbf{- 3 . 1}$ & $\mathbf{- 2 . 4}$ & $\mathbf{- 0 . 9}$ & $\mathbf{0 . 8 2}$ \\
\hline E2/E1 & $\mathbf{0 . 7 7}$ & $\mathbf{0 . 5 6}$ & & \\
\hline
\end{tabular}

Table 2: Storm count by type for each La Niña event in the study. Rainfall anomaly is the averaged standardized rainfall value from the 50 Hawai'ian stations. 


\section{FIGURES}

\subsection{Figure 1: Orientation Map}

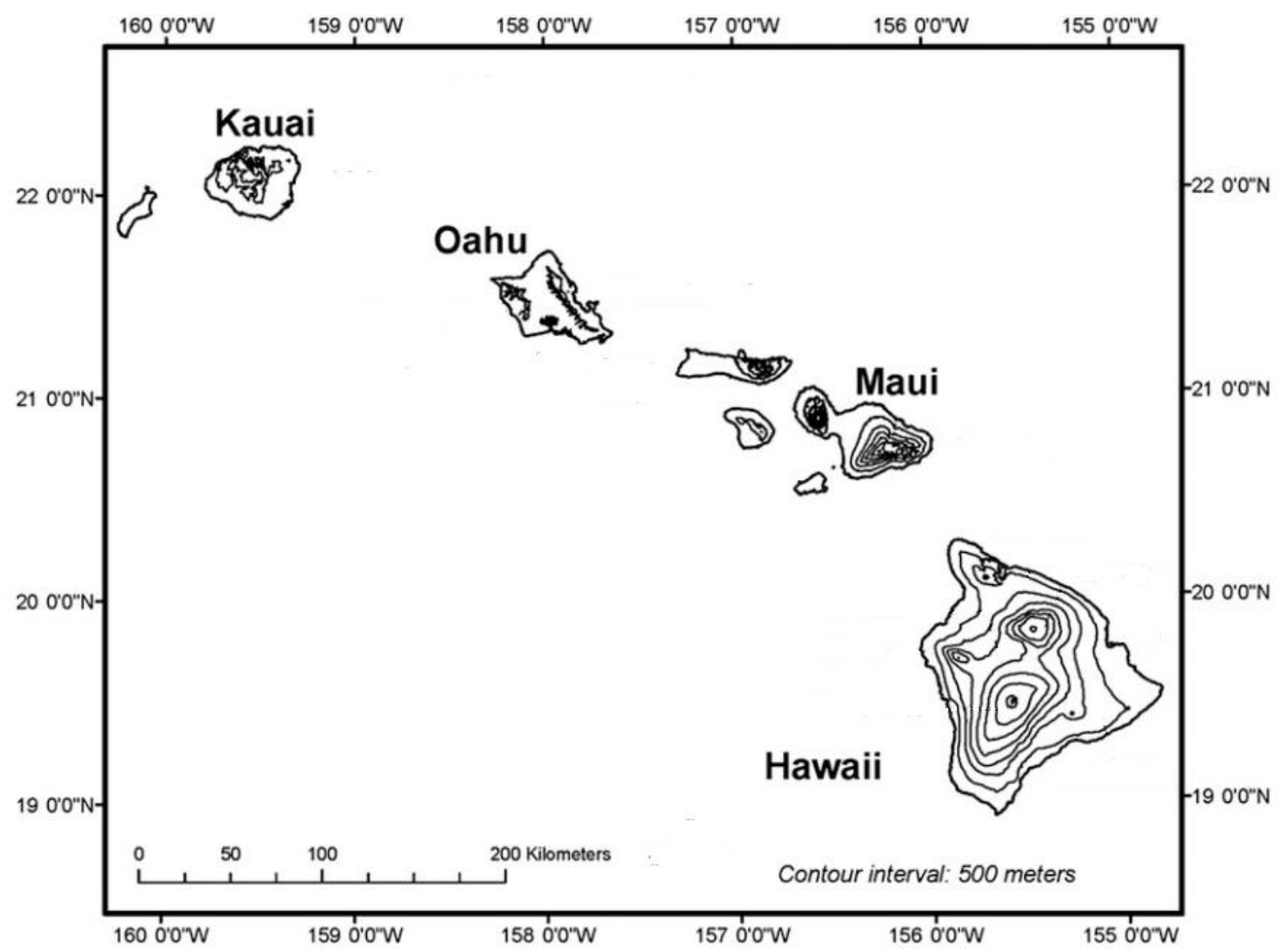

Figure 1: Orientation map of the Hawai'ian Islands; contour interval for elevation is $500 \mathrm{~m}$. 
8.2 Figure 2: Standardized Rainfall Anomalies - Epoch Split

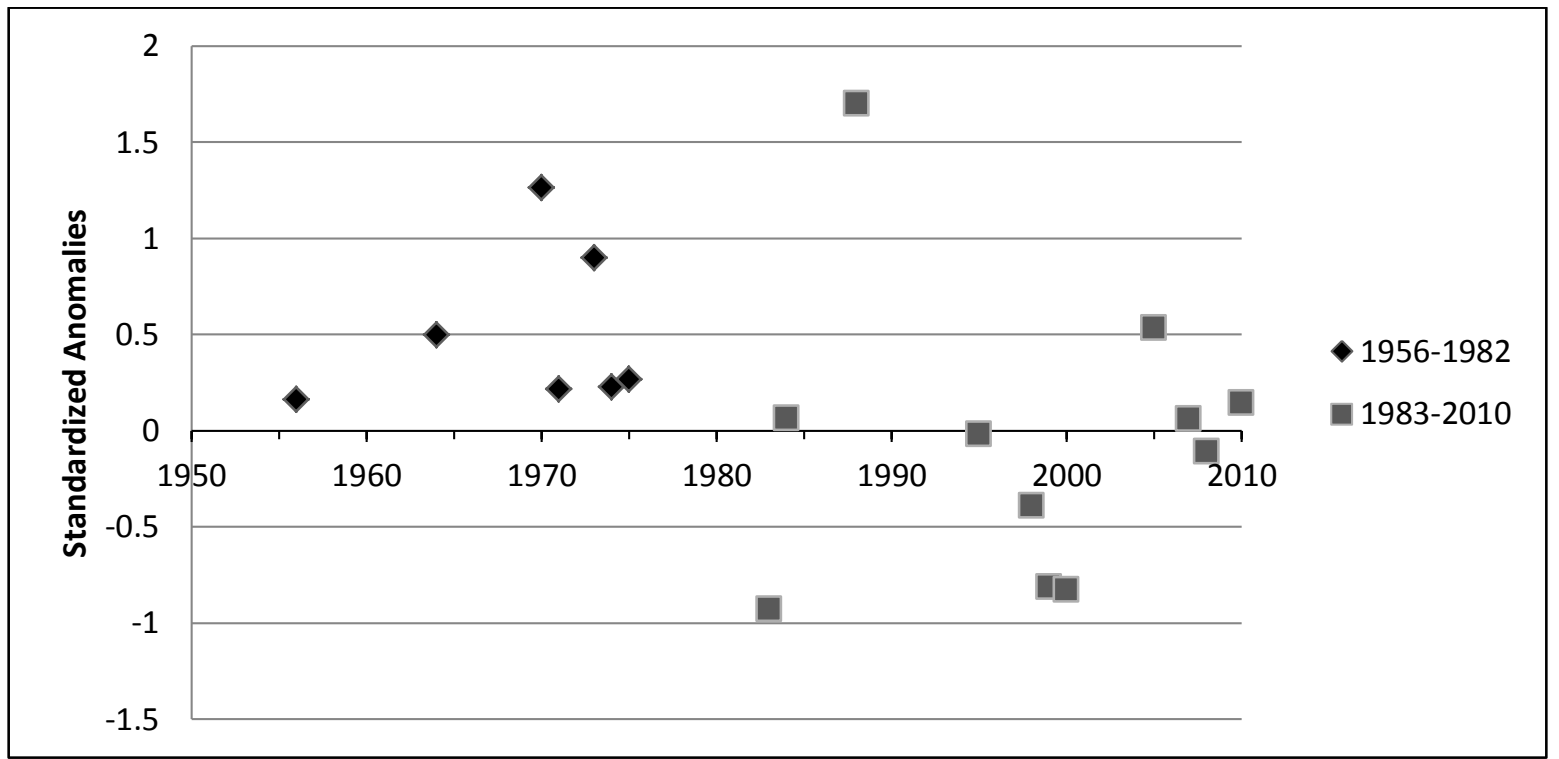

Figure 2: Standardized rainfall anomalies. Epoch 1 (1956-1982) data are black diamonds, while epoch 2 (1983-2010) data are grey squares. Note the drying trend in epoch 2.

\subsection{Figure 3: Standardized Rainfall Anomalies - SST Split}

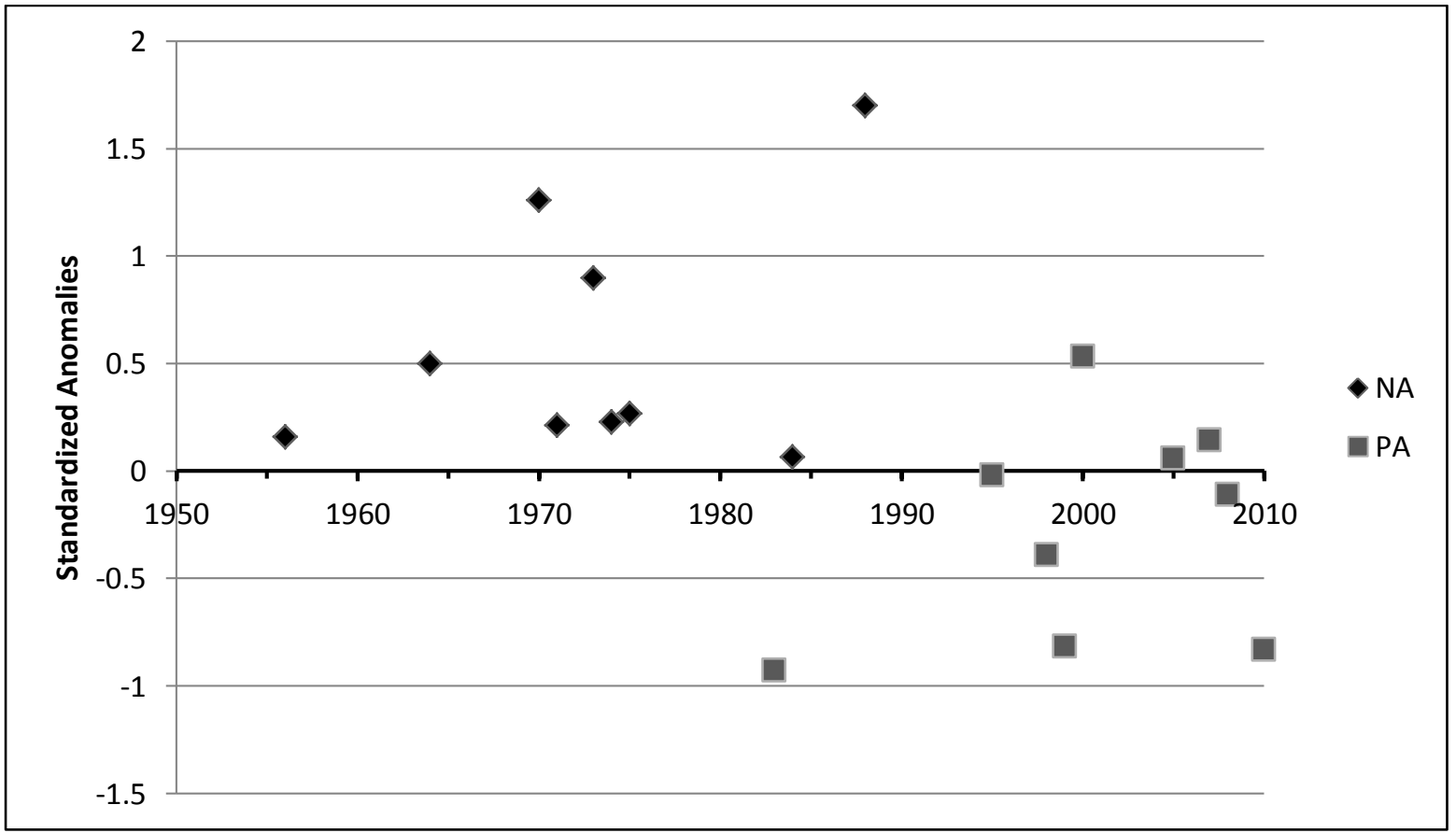

Figure 3: Standardized rainfall anomalies. Negative western Pacific warm pool SST anomalies are black, positive western Pacific warm pool SST anomalies are grey. Note the trend between negative (positive) SST anomalies and wet (dry) rainfall anomalies. 


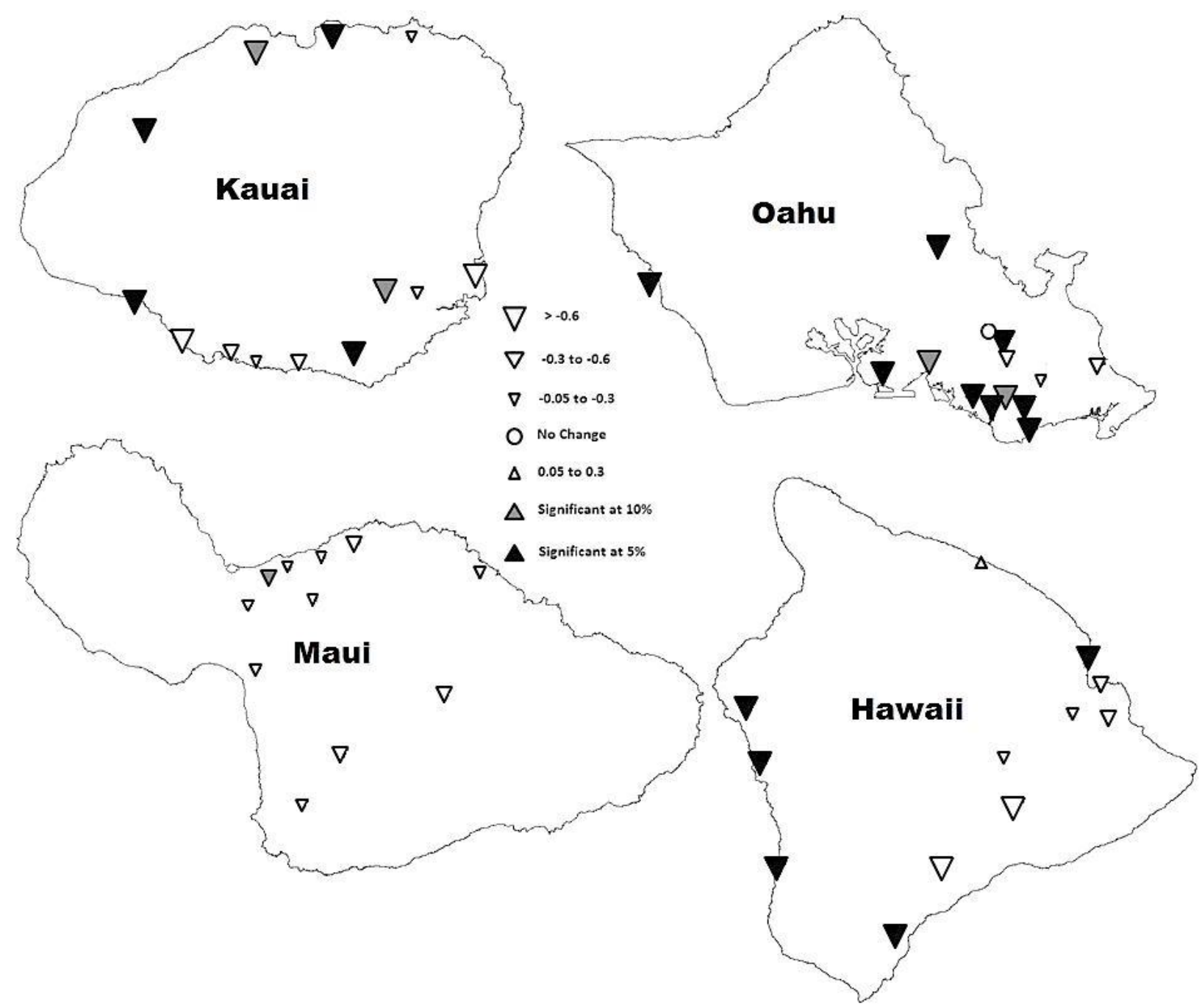

Figure 4: Rain gauge stations are labeled by the triangles and circles. Map legend is in the center of image. Large (medium/small) sized triangles denote strong (moderate/weak) change in rainfall anomalies between epochs. Nonparametric rank sum test significance is indicated by shading, black (grey) shading representing significant change between epochs at the 5\% (10\%) level. 

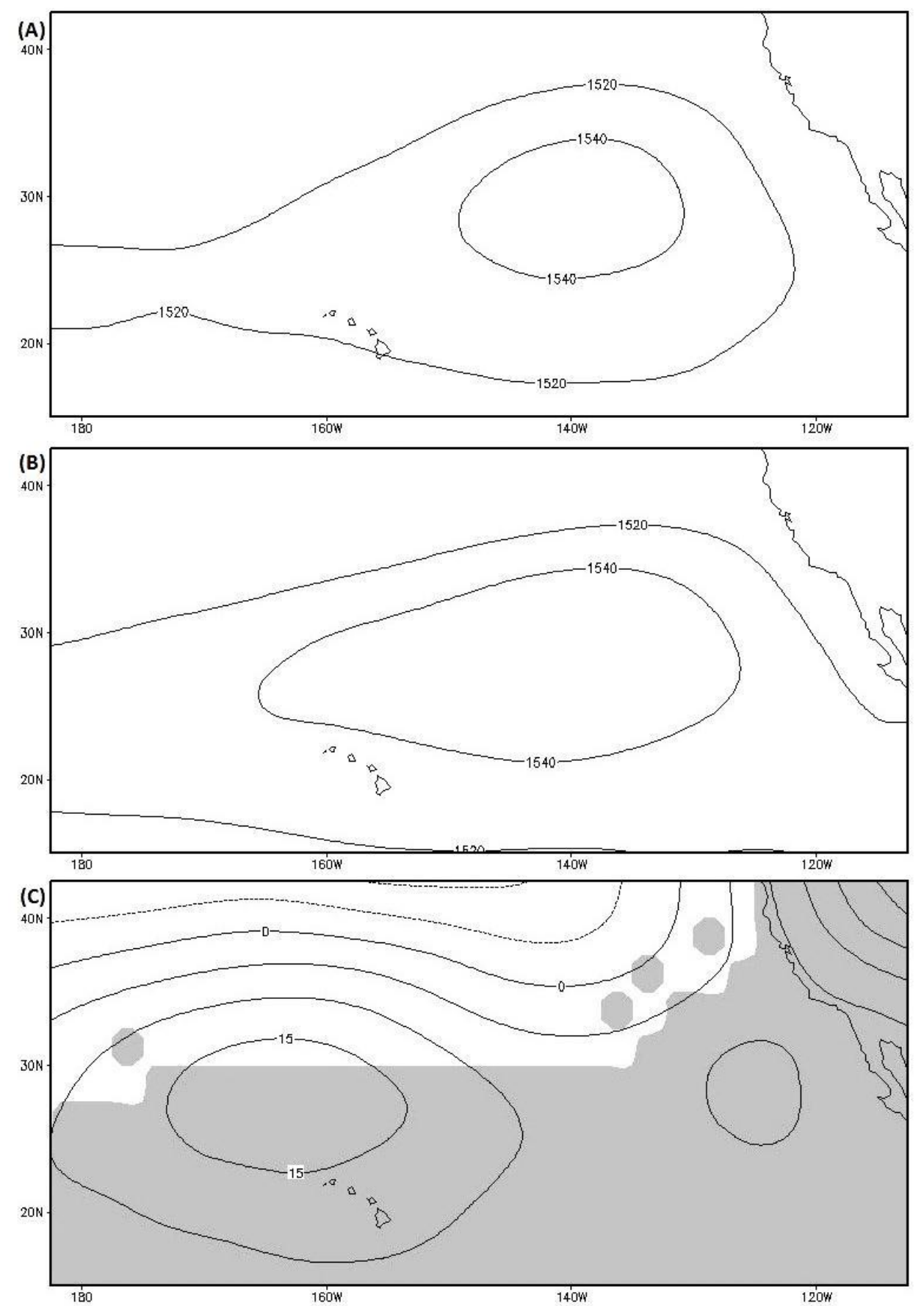

Figure 5: Seasonal mean geopotential height $(\mathrm{m})$ at $850 \mathrm{hPa}$ during La Niña wet seasons. Epoch 1 (1956-1982) is pictured in (a), while Epoch 2 (1983-2010) is pictured in (b). The labeled contour line is $1540 \mathrm{~m}$ and contour intervals are $20 \mathrm{~m}$. Difference in seasonal mean geopotential height at $850 \mathrm{hPa}$ during La Niña wet seasons, epoch 2 minus epoch 1 is pictured in (c). The grey shaded area is where the Wilcoxon-Man-Whitney rank sum test null hypothesis was rejected at the $95 \%$ confidence level. Solid (dashed) contours denote positive (negative) value, and contour intervals are $5 \mathrm{~m}$. 
8.6 Figure 6: Lower Troposphere Winds

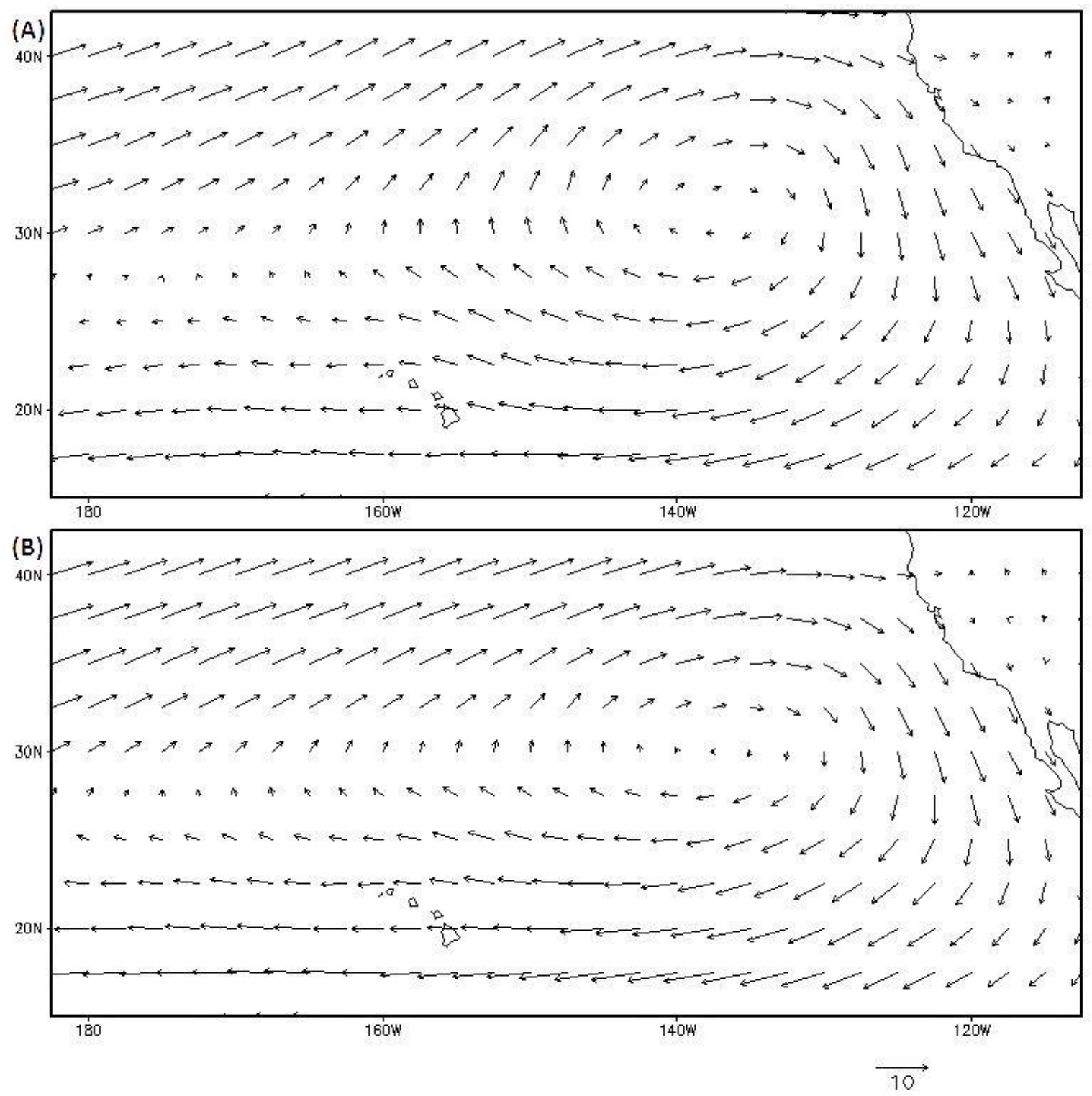

Figure 6: Seasonal mean wind $\left(m s^{-1}\right)$ at $925 \mathrm{hPa}$ during La Niña wet seasons. Epoch 1 (19561982) is pictured in (a), while Epoch 2 (1983-2010) is pictured in (b). 


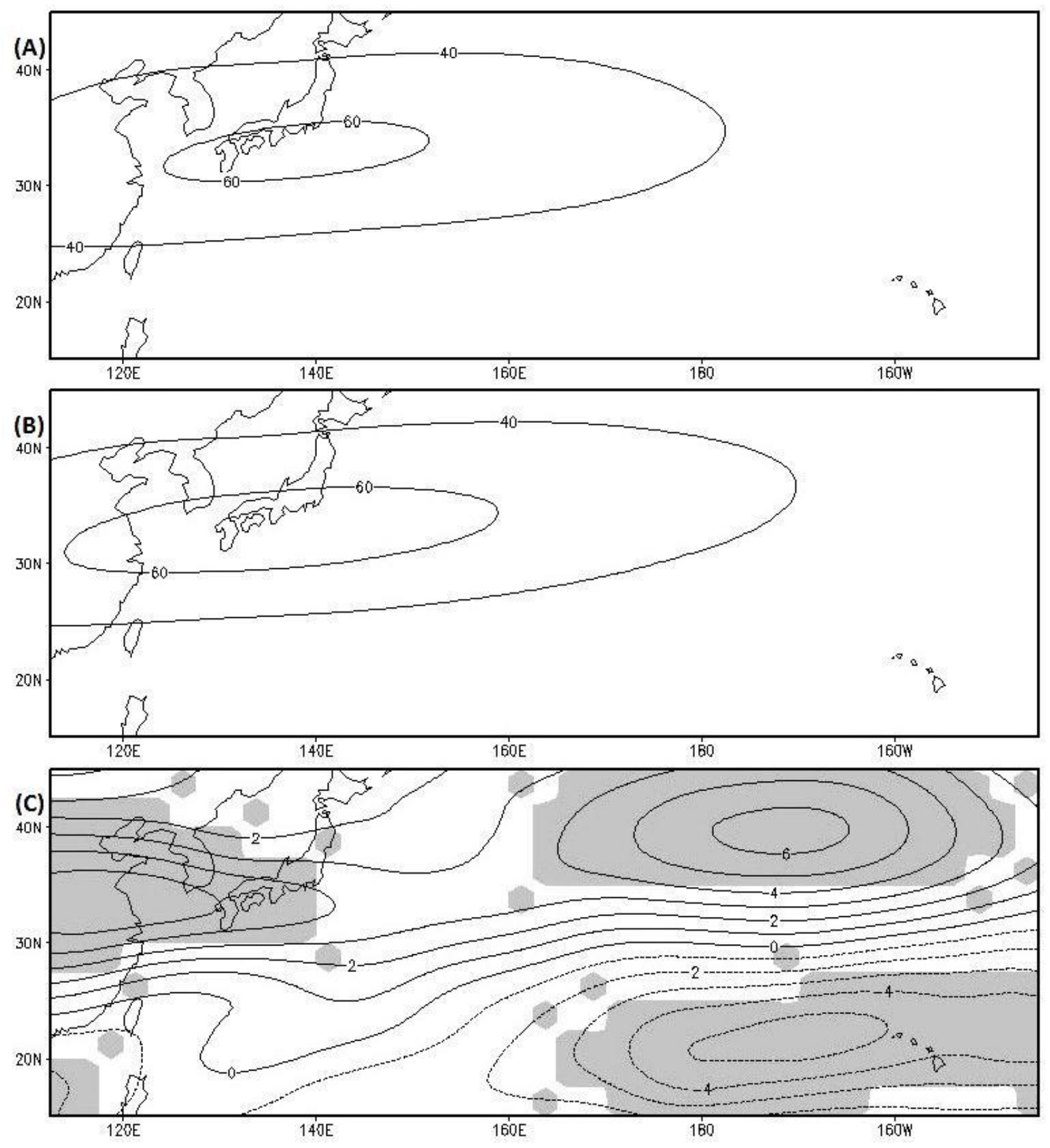

Figure 7: Seasonal mean zonal wind $\left(\mathrm{ms}^{-1}\right)$ at $200 \mathrm{hPa}$ during La Niña wet seasons. Epoch 1 (1956-1982) is pictured in (a), while Epoch 2 (1983-2010) is pictured in (b). The contour intervals are $10 \mathrm{~ms}^{-1}$. Difference in seasonal mean zonal wind during La Niña wet seasons, epoch 2 minus epoch 1 is pictured in (c). The grey shaded area is where the Wilcoxon-ManWhitney rank sum test null hypothesis was rejected at the $95 \%$ confidence level. Solid (dashed) contours denote westerly (easterly) direction. 

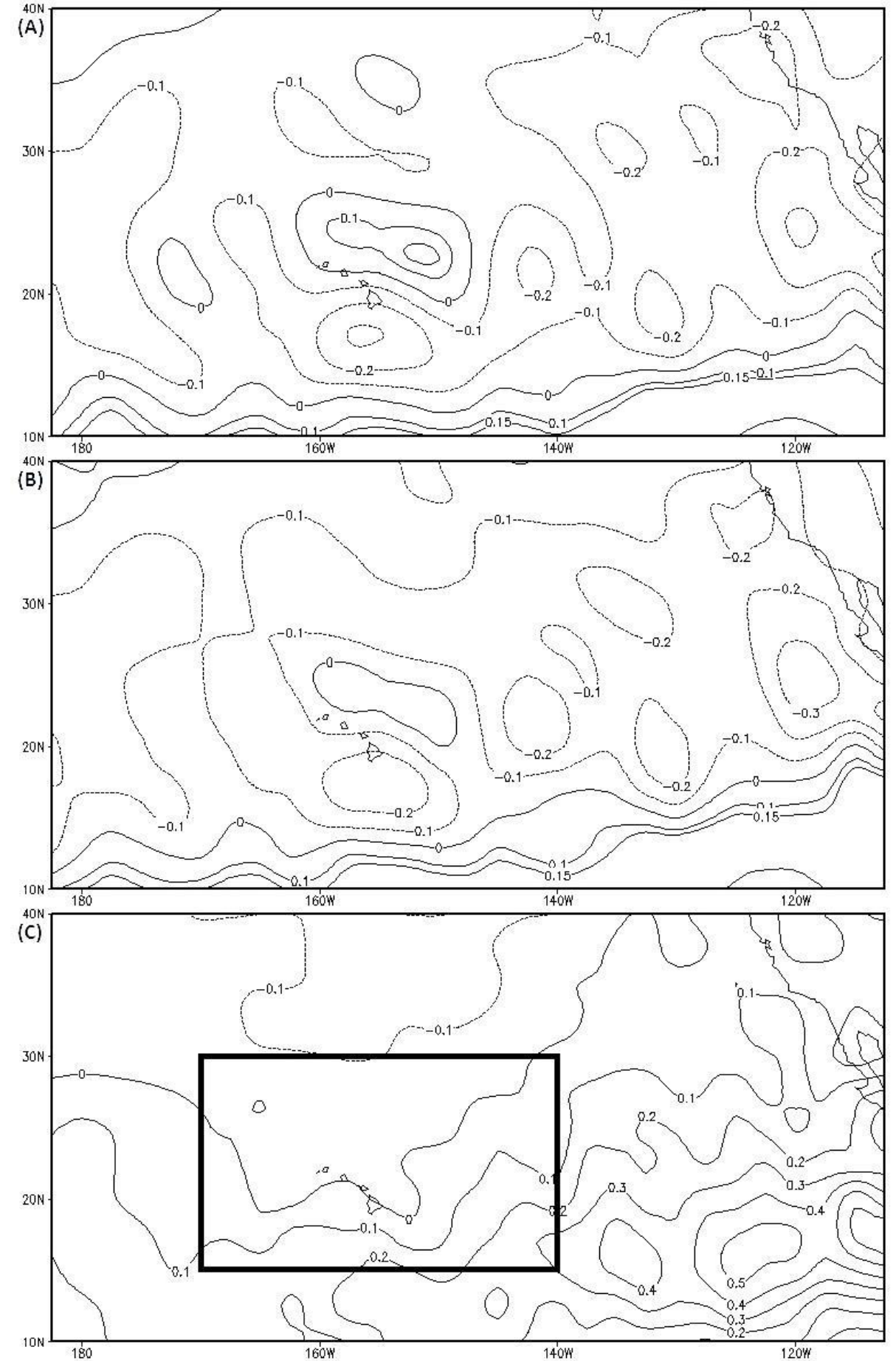

Figure 8: Seasonal mean moisture flux $\left(g\left(\mathrm{~m}^{2} s\right)^{-1}\right)$ during La Niña wet seasons. Epoch 1 (19561982) is pictured in (a), while Epoch 2 (1983-2010) is pictured in (b). Solid (dotted) contours denote moisture convergence (divergence). Difference in seasonal mean moisture flux during La Niña wet seasons, epoch 2 minus epoch 1, is pictured in (c). Solid (dotted) contours denote where difference in seasonal mean moisture flux is positive (negative). The solid black box is domain of Figure 9. 

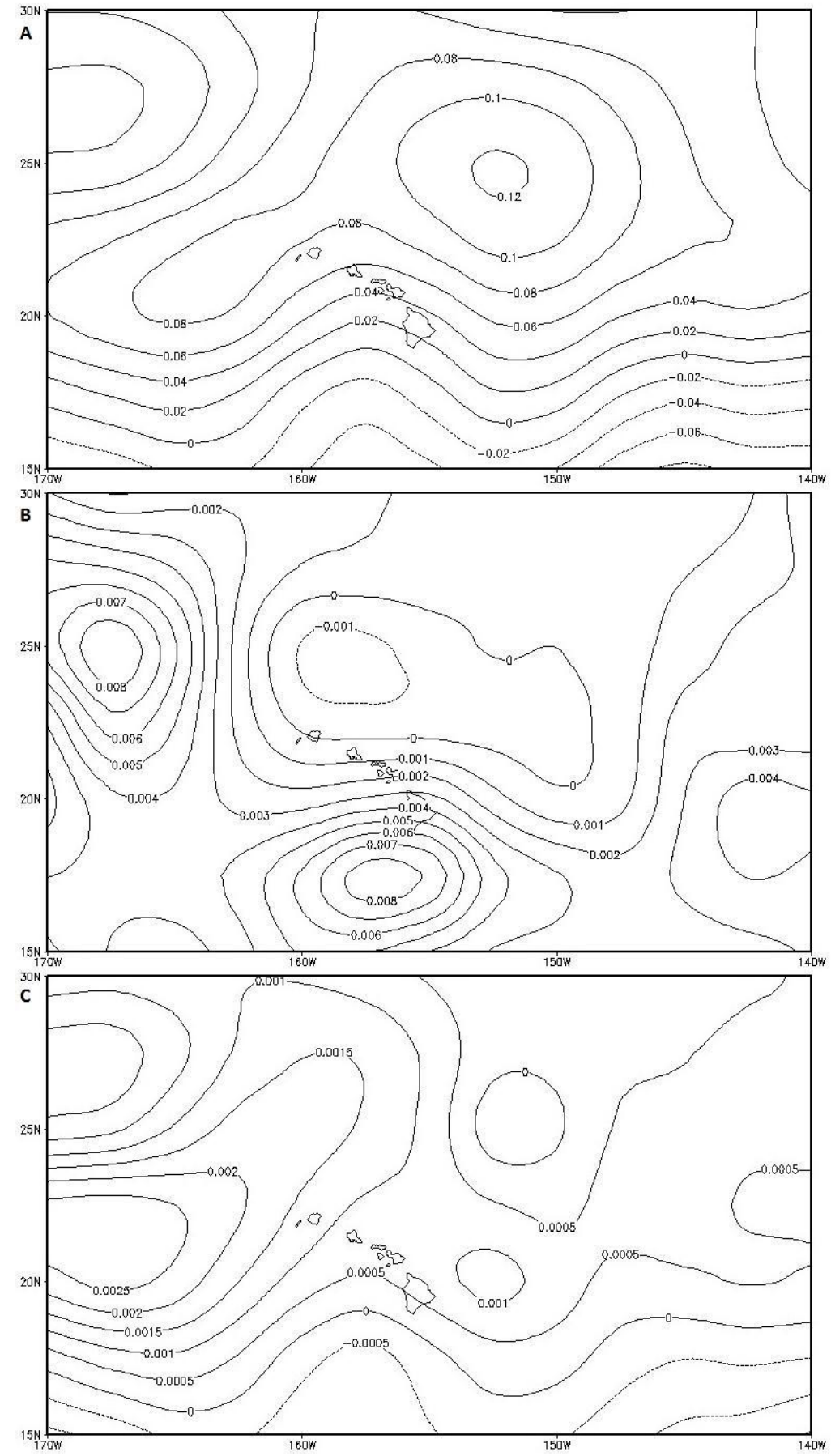

Figure 9: Difference in seasonal mean dynamic effect $\left[g\left(\mathrm{~m}^{2} s\right)^{-1}\right]$ between epochs (E2 minus E1) during La Niña wet seasons is pictured in (a). The area average for (a) is $\left.0.0319 \mathrm{~g}^{2} \mathrm{~m}^{2} \mathrm{~s}\right)^{-1}$. Difference in seasonal mean thermodynamic effect $\left[g\left(\mathrm{~m}^{2} \mathrm{~s}\right)^{-1}\right]$ between epochs (E2 minus E1) during La Niña wet seasons is pictured in (b). The area average for (b) is $\left.0.0025 \mathrm{~g}^{2} \mathrm{~m}^{2}\right)^{-1}$. Difference in seasonal mean nonlinear effect $\left.\left[\mathrm{g} \mathrm{m}^{2} \mathrm{~s}\right)^{-1}\right]$ between epochs (E2 minus E1) during La Niña wet seasons is pictured in (c). The area average for (c) is $0.00046 \mathrm{~g}\left(\mathrm{~m}^{2} \mathrm{~s}\right)^{-1}$. The domain of this analysis can be seen in Fig. 7c, evidenced by the bold black box. 


\subsection{Figure 10: Case Study}
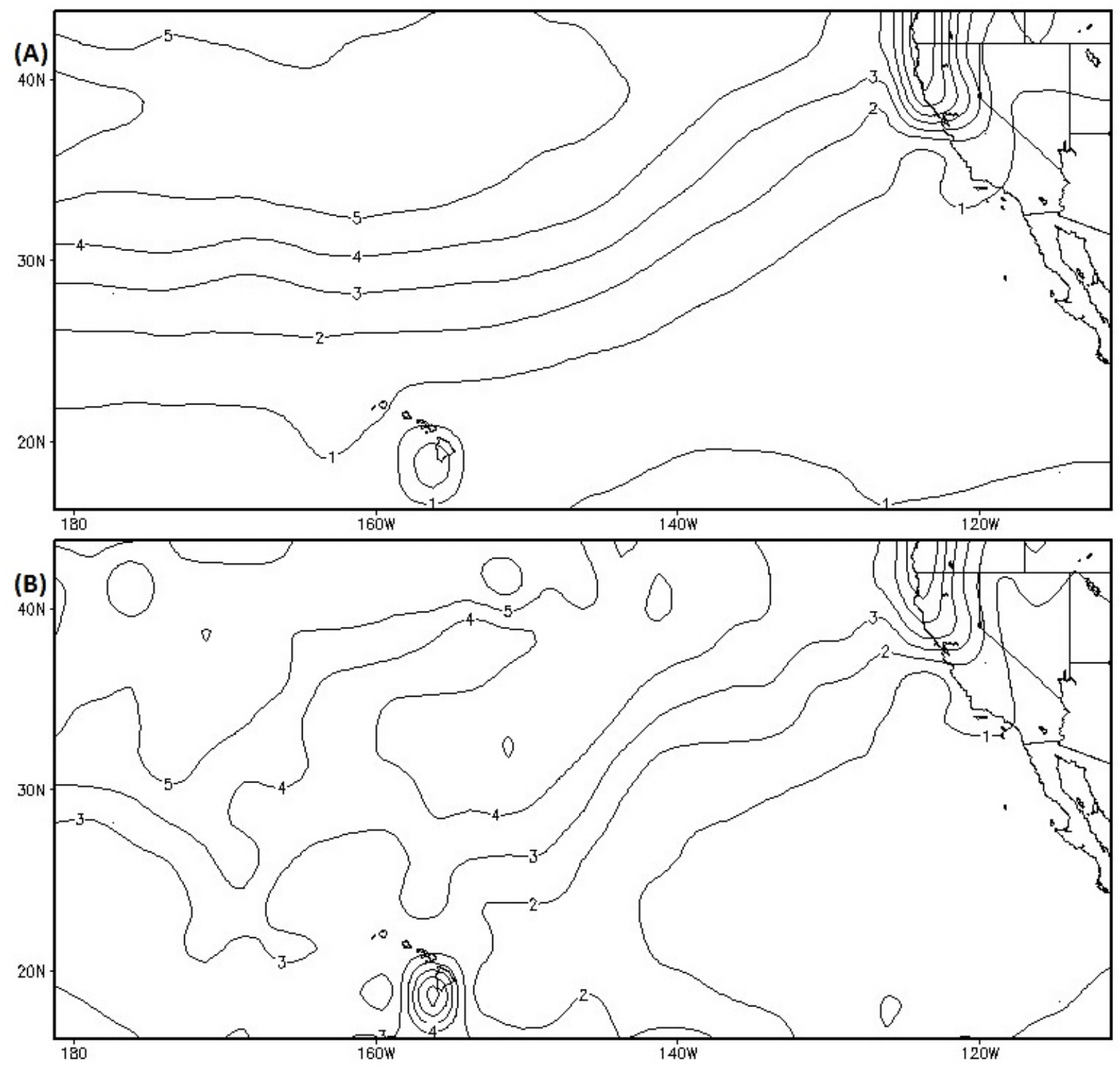

Figure 10: Seasonal mean precipitation $\left(\mathrm{mm} \mathrm{day}^{-1}\right)$ during the 1983-1984 La Niña wet season is pictured in (a). This is a drier than normal La Niña in the Hawai'ian Islands $(z=-0.93)$. Seasonal mean precipitation during the 1988-1989 La Niña wet season is pictured in (b). This is a wetter than normal La Niña in the Hawai'ian Islands $(z=1.70)$. Contour intervals are 1 mm day ${ }^{-1}$. 


\section{APPENDIX A: PETTITT-MANN-WHITNEY STATISTIC - A CHANGE-POINT ANALYSIS}

Every time series with length $N$, given by $\left(X_{t}\right)$, is considered as a sample represented by $X_{1}, X_{2}, \ldots, X_{N}$, where $t$ varies from 1 to $N$. The following indices $V(t)$ and $U(t)$ are then calculated from

$$
\begin{gathered}
V_{t, N}=\sum_{j=1}^{N} \operatorname{sgn}\left(X_{t}-X_{j}\right) \\
U_{t, N}=U_{t-1, N}+V_{t, N} \text { for } t=2, N
\end{gathered}
$$

and

$$
U_{1, N}=V_{1, N}
$$

where $\operatorname{sgn}(x)$ in $\mathrm{Eq}(\mathrm{A} 1)$ is defined as

$$
\operatorname{sgn}(x)=\left\{\begin{array}{c}
1, x>0 \\
0, x=0 \\
-1, x<0
\end{array}\right.
$$

The approximate significance probability $P(t)$ for a change-point is

$$
P(t)=1-\exp \left(-\frac{6 U_{t, N}^{2}}{\left[N^{3}+N^{2}\right]}\right) .
$$

The most significant change-point is found where the significance probability $P(t)$ reaches a maximum. This test is applied to the standardized rainfall values to find the most probable change-point in the period of this study. 


\section{APPENDIX B: A CLASSICAL NONPARAMETRIC TEST FOR THE DIFFERENCE IN LOCATION}

The Wilcoxon-Mann-Whitney rank sum test, also known as the nonparametric MannWhitney $U$ test, is used to evaluate the indicator's differences between two independent data samples [Chu et al., 2010]. The null hypothesis is that there is no significant difference in location between the two data sets. Two batches of sample data have sizes of $n_{1}$ and $n_{2}$. To perform the test, the two data batches needed to be pooled and ranked. Let $U$ be the MannWhitney $U$ statistic:

$$
U=R_{1}-\frac{n_{1}}{2}\left(n_{1}+1\right)
$$

where $R_{1}$ and $R_{2}$ are defined as the sum of the ranks held by the two batches. The null distribution of the Mann-Whitney $U$ statistic is approximately Gaussian when $n_{1}$ and $n_{2}$ are moderately large with

$$
\begin{gathered}
\mu_{U}=\frac{n_{1} n_{2}}{2} \text { and } \\
\sigma_{U}=\left[\frac{n_{1} n_{2}\left(n_{1}+n_{2}+1\right)}{12}\right]^{1 / 2}
\end{gathered}
$$

Once $\mu_{U}, \sigma_{U}$, and $U$ are computed, the $U$ statistic is transformed into a standard Gaussian variable and is evaluated for its statistical significance. The null hypothesis is rejected when the resulting $\mathrm{p}$-value is less than 0.05 , the normal test level. If the null hypothesis is rejected, the two datasets are significantly different at a 95\% confidence level. The Wilcoxon-Mann-Whitney rank sum test is applied to the normalized rainfall data, the NCEP Reanalysis I datasets, and the storm track analysis. 


\section{REFERENCES}

Ashok, K., S. K. Behera, S. A. Rao, H. Weng, and T. Yamagata, 2007: El Niño Modoki and its possible teleconnection. J. Geophys. Res., 112, C11007, doi:10.1029/2006JC003798.

Bassiouni, M. and D. S. Oki, 2012: Trends and shifts in streamflow in Hawai'i, 1913-2008. Hydrological Processes, 27, 1484-1500.

Caruso, S. J., and S. Businger, 2006: Subtropical cyclogenesis over the central North Pacific. Wea. Forecasting, 21, 193-205.

Chu, P.-S., 1995: Hawai'i rainfall anomalies and El Niño. J. Climate, 8, 1697-1703.

Chu, P.-S., and H. Chen, 2005: Interannual and interdecadal rainfall variations in the Hawai'ian Islands. J. Climate, 18, 4796-4813.

Chu, P.-S., W. Yan, and F. Fujioka, 2002: Fire-climate relationships and long-lead wildfire prediction for Hawai'i. Int. J. Wildland Fire, 11, 25-31.

Chu, P.-S., Y. R. Chen, and T.A. Schroeder, 2010: Changes in precipitation extremes in the Hawai'ian Islands in a warming climate. J. Climate, 23, 4881-4900.

Dolling, K., P.-S. Chu, and F. Fujioka, 2009: Natural variability of the Keetch/Byram drought index in the Hawai'ian Islands. Int. J. Wildland Fire, 18, 459-475.

FAO. 2008. Climate change and food security in Pacific island countries. Food and Agriculture Organization of the United Nations: Rome, Italy. 280 pp, ftp://ftp.fao.org/docrep/fao/011/i0530e.

Garza, J., P.-S. Chu, C. Norton, and T.A. Schroeder, 2012: Changes of the prevailing trade winds over the Islands of Hawai'i and the North Pacific. J. Geophys. Res. (Atmospheres), 117, D11109, doi: 10.1029/2011JD016888.

He, X.-Z. and D.-Y. Gong, 2002: Interdecadal change in western Pacific subtropical high and climatic effects. J. of Geograph. Sci., 12, 202-209.

Hu, Z.-Z., A. Kumar, B. Jha, W. Wang, B. Huang, and B. Huang, 2012: An analysis of warm pool and cold tongue El Niños: Air-sea coupling processes, global influences, and recent trends. Climate Dyn., 38, 2017-2035, doi:10.1007/s00382-011-1224-9.

Junker, Norman W., Richard H. Grumm, Robert Hart, Lance F. Bosart, Katherine M. Bell, Frank J. Pereira, 2008: Use of normalized anomaly fields to anticipate extreme rainfall in the mountains of northern California. Wea. Forecasting, 23, 336-356. 
Kanamitsu, M., W. Ebisuzaki, J. Woollen, S.-K. Yang, J. J. Hnilo, M. Fiorino, and G. L. Potter 2002: NCEP-DOE AMIP-II Reanalysis (R-2), Bull. Am. Meteorol. Soc., 83, 1631-1643, doi:10.1175/BAMS-83-11-1631.

Kruk, M. C., A. Lorrey, G. M. Griffiths, M. Lander, E. Gibney, H. Diamond, and J. J. Marra, 2014: Review on the state of the knowledge of rainfall extremes in the western and northern Pacific basin. Int. J. Climatol., DOI: 10.1002/joc.3990.

Li, W., Li, L., Fu, R., Deng, Y. \& Wang, H., 2011: Changes to the North Atlantic subtropical high and its role in the intensification of summer rainfall variability in the Southeastern United States. J. Climate., 24, 1499-1506.

Lu, R., and Dong, B., 2001: Westward extension of North Pacific subtropical high in summer. J. Meteorol. Soc. Jpn., 79, 1229-1241.

Nakamura, H., 1992: Midwinter suppression of baroclinic wave activity in the Pacific. J. Atmos. Sci., 49, 1629-1642.

M. J. Nazemosadat, N. Samani, D. A. Barry, and M. Molaii Niko, 2006: ENSO forcing on climate change in Iran: Precipitation analysis. Iranian J. of Sci. \& Tech., 30, 555-565.

Norton, C., P.-S. Chu, and T. A. Schroeder, 2011: Estimating changes in future heavy rainfall events for Oahu, Hawai'i: A statistical downscaling approach. J. Geophys. Res. (Atmospheres), 116, D17110, doi: 10.1029/2011JD015641.

Otkin, J. A., and J. E. Martin, 2004: A synoptic climatology of the subtropical Kona storm. Mon. Wea. Rev., 132, 1502-1517.

Ramage, C.S., 1962: The subtropical cyclone. J. Geophys. Res., 67, 1401-1411. doi:10.1029/JZ067I004P01401

Ropelewski, C.F., M.S. Halpert, 1987: Global and regional scale precipitation patterns associated with the El Niño/Southern Oscillation. Mon. Wea. Rev., 115, 1606-1626.

Ruti, P.M., V. Lucarini, A. Dell'Aquila, S. Calmanti, A. Speranza, 2006: Does the subtropical jet catalyze the midlatitude atmospheric regimes?, Geophys. Res. Lett., 33, L06814.

Schroeder, T. A., 1993: Climate controls, in prevailing trade winds, edited by M. Sanderson, pp. 12-36, Univ. of Hawai'i Press, Honolulu.

Strong, C., and R. Davis, 2007: Winter jet stream trends over the Northern Hemisphere. Q. J. R. Meteorol. Soc., 133, 2109-2115. 
Timm, O., H. F. Diaz, 2009: Synoptic-Statistical Approach to Regional Downscaling of IPCC Twenty-First-Century Climate Projections: Seasonal Rainfall over the Hawai'ian Islands. J. Climate, 22, 4261-4280.

Trenberth, K. E., and J. M. Caron, 2000: The Southern Oscillation revisited: Sea level pressures, surface temperatures, and precipitation. J. Climate, 13, 4358-4365.

Trenberth, K. E., 1997: The definition of El Niño. Bull. Amer. Meteor. Soc., 78, 2771-2777.

Trenberth, K.E., and D. P. Stepaniak, 2001: Indices of El Niño evolution, J. Climate, 14, 16971701.

Yeh, S.-W., J.-S. Kug, B. Dewitte, M.-H. Kwon, B. P. Kirtman, and F.-F. Jin, 2009: El Niño in a changing climate., Nature, 461, 511-514.

Yu, J.-Y., and H.-Y. Kao, 2007: Decadal changes of ENSO persistence barrier in SST and ocean heat content indices: 1958-2001. J. of Geophys. Res., 112, D13106.

Zhang, X., J. Walsh, J. Zhang, U. S. Bhatt, M. Ikeda, 2004: Climatology and interannual variability of Artic cyclone activity: 1948-2002. J. Climate, 17, 2300-2316. 